Matthias Linnemann, Pavel Anatolyevich Nikolaychuk, Y. Mauricio Muñoz-Muñoz, Elmar Baumhögger, Jadran Vrabec

\title{
Henry's Law Constant of Noble Gases in Water, Methanol, Ethanol, and Isopropanol by Experiment and Molecular Simulation
}

Journal article | Accepted manuscript (Postprint)

This version is available at https://doi.org/10.14279/depositonce-9905

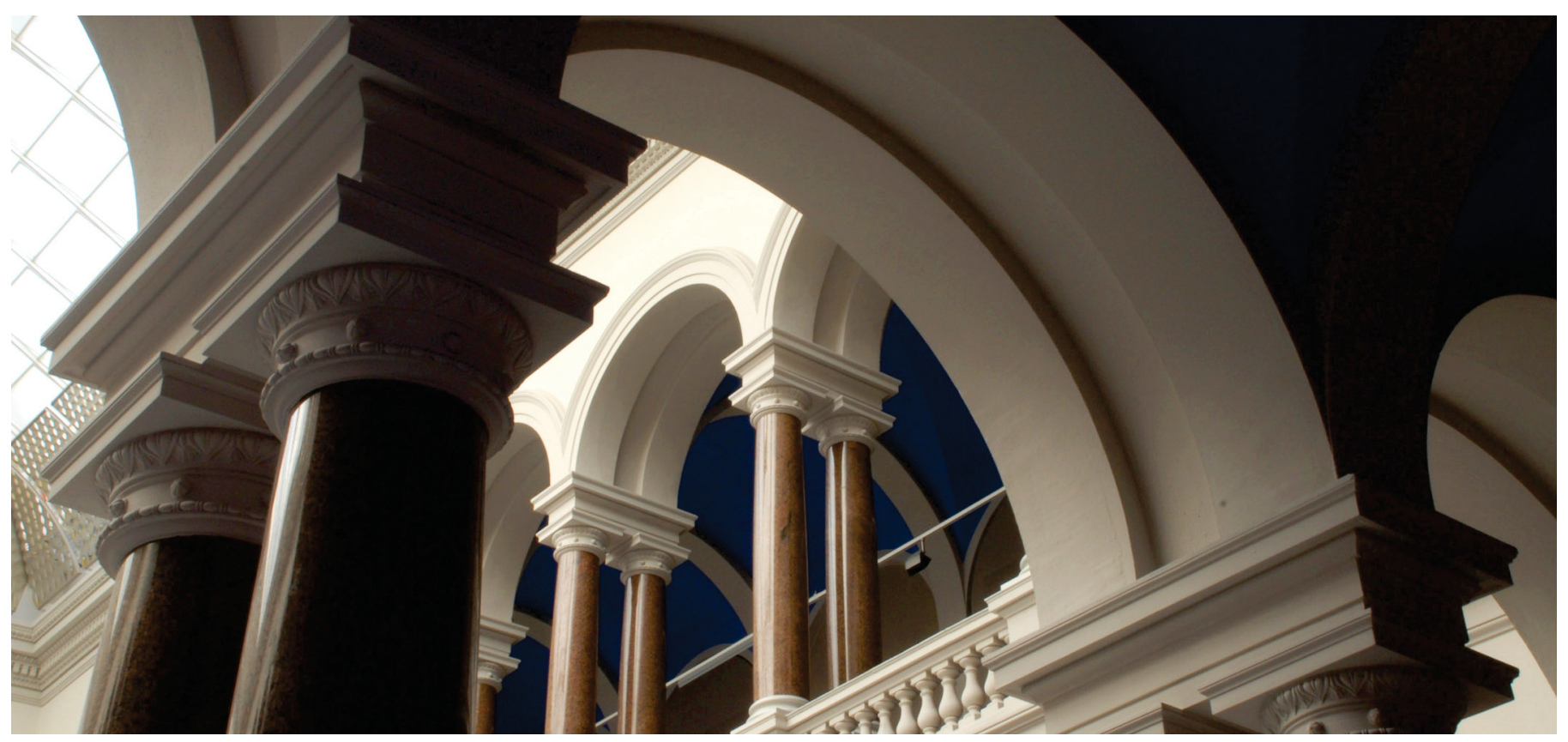

Linnemann, M., Nikolaychuk, P. A., Muñoz-Muñoz, Y. M., Baumhögger, E., \& Vrabec, J. (2019). Henry's Law Constant of Noble Gases in Water, Methanol, Ethanol, and Isopropanol by Experiment and Molecular Simulation. Journal of Chemical \& Engineering Data, 65(3), 1180-1188.

https://doi.org/10.1021/acs.jced.9b00565 


\title{
Henry's Law Constant of Noble Gases in
}

\section{Water, Methanol, Ethanol and Isopropanol by Experiment and Molecular Simulation}

\author{
Matthias Linnemann, ${ }^{\dagger}$ Pavel Anatolyevich Nikolaychuk, ${ }^{\ddagger} \mathrm{Y}$. Mauricio \\ Muñoz-Muñoz, ${ }^{\ddagger}$ Elmar Baumhögger, ${ }^{\ddagger}$ and Jadran Vrabec ${ }^{*, \dagger}$ \\ $\dagger$ Thermodynamics and Process Engineering, Technical University of Berlin, \\ Ernst-Reuter-Platz 1, 10623 Berlin, Germany \\ $\ddagger$ Thermodynamics and Energy Technology, University of Paderborn, Warburger Straße 100, \\ 33098 Paderborn, Germany \\ E-mail: vrabec@tu-berlin.de \\ Phone: +49 (0)30 314-22755. Fax: +49 (0)30 314-22406
}

\begin{abstract}
Henry's law constant data for the noble gases helium, neon, argon, krypton, xenon and radon in the pure solvents water, methanol, ethanol and propan-2-ol are predicted over a wide temperature range by molecular simulation. Furthermore, gas solubility measurements are carried out for neon, krypton and xenon in propan-2-ol, yielding experimental Henry's law constant values that are employed, together with data from literature, to evaluate present simulation results. Suitable molecular force field models are identified for each binary system and new models for helium and neon are presented. By examining the entire set of binary systems, a characteristic trend of the solubility behavior concerning the molecular size of the solutes and solvents is identified. The
\end{abstract}


present work contributes consistent Henry's law constant data for 24 binary solutesolvent pairs over the entire relevant temperature range and improves the database considerably.

\section{Introduction}

The precise knowledge of phase equilibrium behavior is essential for the design of numerous chemical engineering applications, such as distillation, pervaporation, ab- and desorption. ${ }^{1,2}$ Especially phase equilibrium data of mixtures are crucial for the industry and the successful implementation of various research projects, ${ }^{3,4}$ but are often not available for the relevant systems. Consequently, a further investigation of these properties is necessary to increase the operational range of existing applications as well as for the development of innovative

products and processes. ${ }^{5}$ In this way, resources can be saved, supporting a sustainable treatment of the environment. In this context, a growing interest in the utilization of noble gases in technical applications can be observed because of their chemical inertness, but also due to their unique physical properties that allow for their usage in electronics and especially in the field of lighting. ${ }^{6}$ Moreover, in conjunction with non-toxicity, these characteristics led to an increasing interest for the use of noble gases in medicine and pharmaceutics. ${ }^{7}$

For many applications, the solubility of noble gases in liquids, which can be described by means of Henry's law, ${ }^{8}$ is of particular interest. ${ }^{9}$ However, gas solubility data for relevant solvents have only been reported for a limited temperature range.

In preceding publications of our group, ${ }^{10,11}$ Henry's law constant data for the solutes helium (He) and argon ( $\mathrm{Ar})$ in propan-2-ol (2-PrOH) were determined over a temperature range from 254 to $482 \mathrm{~K}$ by experiment and molecular simulation. These experiments were continued in the present work, considering neon (Ne), krypton (Kr) and xenon (Xe) in propan-2-ol. For the present experiments, a high temperature gas solubility apparatus was employed, which relies on the synthetic method to measure state points on the saturated liquid line over a temperature range between 320 and $480 \mathrm{~K}$. 
However, these experiments are time-consuming and laborious so that other methods need to be employed to provide Henry's law constant data over the entire temperature range and for further solvents. It is known from the literature that molecular simulation, based on intermolecular force fields and statistical mechanics, is particularly suitable to predict a wide range of thermodynamic properties with an adequate accuracy. ${ }^{12}$ Thus, the simulation tool $m s 2^{13}$ was employed here together with validated molecular force field models to predict Henry's law constant data for the entire set of noble gases helium, neon, argon, krypton, xenon and Radon $(\mathrm{Rn})$ in the pure solvents water $\left(\mathrm{H}_{2} \mathrm{O}\right)$, methanol $(\mathrm{MeOH})$, ethanol (EtOH) and propan-2-ol in a systematic way. Subsequently, the simulation results are discussed and compared with the experimental values of this work and from the literature, where it is shown that the predicted Henry's law constant data are consistent over a wide temperature range and significantly extend the database for 24 solute-solvent pairs.

\section{Experiments}

Gas solubility measurements were conducted with an apparatus that was initially described by Windmann et al. ${ }^{14}$ and was subsequently employed by our group to study various mixtures. ${ }^{10,11,15}$ A detailed description of the measuring procedure was presented in these publications so that only its basic principles are outlined here. The synthetic method was used, which means that the masses of the pure components loaded into the measuring cell were precisely determined, leading to the mole fraction of the binary mixture. The vapor-liquid equilibrium at a specified temperature was reached by composing a mixture where only a negligibly small vapor bubble remains in the liquid phase, which represents a state on the saturated liquid line. Consequently, the measured pressure in the cell at this state point is the one of the phase equilibrium. 


\section{Materials}

The solvent propan-2-ol was purchased from Merck with a purity of $\geq 99.8 \%$, which was confirmed by gas chromatographic analysis in our lab. Furthermore, the solvent was degassed under vacuum before the present experimental work, while the employed noble gases were not further purified. Sample information, including the purity as given by the supplier, is summarized in Table 1.

Table 1: Sample information.

\begin{tabular}{lllll}
\hline \hline fluid & CAS registry number & source & purification method & minimum purity \\
\hline neon & $7440-01-9$ & Air Liquide & none & $99.999 \%$ \\
krypton & $7439-90-9$ & Linde & none & $99.99 \%$ \\
xenon & $7440-63-3$ & Air Liquide & none & $99.99 \%$ \\
propan-2-ol & $67-63-0$ & Merck & degassing & $99.8 \%$ \\
\hline \hline
\end{tabular}

a according to supplier

\section{Experimental uncertainties}

Platinum resistance thermometers with a basic resistance of $100 \Omega$ were used for the temperature measurements that led to a standard uncertainty of $u(T)=0.04 \mathrm{~K}$. The pressure in the measuring cell was determined with a pressure transducer from Honeywell Test \& Measurement (model Super TJE) that had a measuring scale of $70 \mathrm{MPa}$ and an accuracy of $0.1 \%$ of the full scale so that the standard uncertainty of the phase equilibrium pressure was $u(p)=0.07 \mathrm{MPa}$. Pressure transducers of the same type were employed to determine the quantities of the pure components that were loaded into the cell. However, for the gaseous component inlet, the measuring scale of the pressure transducer was $20 \mathrm{MPa}$ for experiments with neon and 1.3 MPa for experiments with krypton and xenon, while for the liquid component inlet, a pressure transducer with a measuring scale of $100 \mathrm{MPa}$ was employed. In addition to the uncertainties of the temperature and pressure measurements, the uncertainties of the equations of state (EOS), ${ }^{16-18}$ that were used to calculate the density of the pure components, had to be considered to determine the uncertainty of the amount of the 
solute and solvent, i.e. $u\left(n_{\text {gas }}\right)$ and $u\left(n_{\text {liq }}\right)$, respectively. Based on these data, the standard uncertainty of the solute mole fraction $u\left(x_{\text {gas }}\right)$ was calculated with the error propagation law

$$
u\left(x_{\text {gas }}\right)=\sqrt{\left(\frac{\partial x_{\text {gas }}}{\partial n_{\text {gas }}} u\left(n_{\text {gas }}\right)\right)^{2}+\left(\frac{\partial x_{\text {gas }}}{\partial n_{\text {liq }}} u\left(n_{\text {liq }}\right)\right)^{2}} .
$$

\section{Molecular simulations}

\section{Molecular models}

To predict the Henry's law constant by molecular simulation, suitable molecular force field models have to be employed. Molecular models from Abascal et al., ${ }^{19}$ Schnabel et al. ${ }^{20,21}$ and Nikolaychuk et al. ${ }^{10}$ were used for the solvents water, methanol, ethanol and propan-2-ol, respectively. Furthermore, the force field parameters of these molecular models are given in the supporting information. The noble gases were modeled with a single Lennard-Jones (LJ) site throughout. However, different values for the LJ energy parameter $\epsilon$ and LJ size parameter $\sigma$ can be found in the literature. Parameters of Warr et al. ${ }^{22}$ were employed for

helium, neon, argon, krypton and xenon, those of Vrabec et al. ${ }^{23}$ for argon, krypton and xenon, while parameters of Mick et al. ${ }^{24}$ were employed for radon. Moreover, the present work provides new LJ parameters for helium and neon that were adjusted here to achieve a better agreement with the experimental Henry's law constant values. The procedure to specify these parameters is given in the supporting information and the employed LJ parameters are listed in Table 2.

To describe the interaction between unlike molecules $\mathrm{A}$ and $\mathrm{B}$, the LJ parameters $\sigma_{\mathrm{AB}}$ and $\epsilon_{\mathrm{AB}}$ were specified with the Lorentz-Berthelot combination rule ${ }^{25,26}$

$$
\sigma_{\mathrm{AB}}=\frac{\sigma_{\mathrm{A}}+\sigma_{\mathrm{B}}}{2}
$$

and 
Table 2: Lennard-Jones parameters of the noble gas solutes.

\begin{tabular}{|c|c|c|c|}
\hline fluid & model & $\begin{array}{l}\sigma \\
\AA\end{array}$ & $\begin{array}{c}\epsilon / k_{B} \\
\mathrm{~K}\end{array}$ \\
\hline helium & $\begin{array}{l}\text { Warr et al. } \\
\text { this work }\end{array}$ & $\begin{array}{l}2.967 \\
2.952\end{array}$ & $\begin{array}{l}10.8 \\
6.934\end{array}$ \\
\hline neon & $\begin{array}{l}\text { Warr et al. } \\
\text { this work }\end{array}$ & $\begin{array}{l}3.087 \\
3.048\end{array}$ & $\begin{array}{l}42.25 \\
23.867\end{array}$ \\
\hline argon & $\begin{array}{l}\text { Warr et al. }{ }^{22} \\
\text { Vrabec et al. }\end{array}$ & $\begin{array}{l}3.759 \\
3.3952\end{array}$ & $\begin{array}{l}143.2 \\
116.79\end{array}$ \\
\hline krypton & $\begin{array}{l}\text { Warr et al. }{ }^{22} \\
\text { Vrabec et al. }\end{array}$ & $\begin{array}{l}3.759 \\
3.6274\end{array}$ & $\begin{array}{l}143.2 \\
162.58\end{array}$ \\
\hline xenon & $\begin{array}{l}\text { Warr et al. }{ }^{22} \\
\text { Vrabec et al. }\end{array}$ & $\begin{array}{l}4.063 \\
3.9011\end{array}$ & $\begin{array}{l}282.35 \\
227.55\end{array}$ \\
\hline radon & Mick et al. ${ }^{24}$ & 4.145 & 292.0 \\
\hline
\end{tabular}

$$
\epsilon_{\mathrm{AB}}=\sqrt{\epsilon_{\mathrm{A}} \cdot \epsilon_{\mathrm{B}}}
$$

In this way, all simulation data for the Henry's law constant are predictive because no binary interaction parameters were introduced.

\section{Simulation details}

Monte Carlo simulations were carried out employing the simulation tool $m s 2$, release $3.0 .^{13}$ For the prediction of the Henry's law constant, the isobaric-isothermal $(N p T)$ ensemble of the solvent's saturated liquid state with $N=864$ particles and a cutoff radius of $15 \AA$ was used. The Henry's law constant $H_{i}$ is dominated by the residual chemical potential at infinite dilution $\mu_{i}^{\infty 27}$

$$
H_{i}=\rho_{\mathrm{s}} k_{\mathrm{B}} T \exp \left(\frac{\mu_{i}^{\infty}}{k_{\mathrm{B}} T}\right)
$$

where $\rho_{\mathrm{s}}$ is the saturated liquid density of the solvent, $T$ the temperature and $k_{\mathrm{B}}$ Boltzmann's constant. To sample a state of infinite dilution, simulations of pure solvents were conducted in the $N p T$ ensemble, while the solutes were only inserted as test particles with Widom's 
method $^{28}$ after each Monte Carlo cycle. For each simulation, $2 \times 10^{4}$ equilibration and $3 \times$ $10^{6}$ production cycles were carried out. Furthermore, the reaction field method with tin-foil boundary conditions was employed to consider electrostatic long-range interactions, while dispersion effects were taken into account by the analytical mean field correction. Typical input files from the present simulations using the tool $m s 2$ are given in the supporting information and further details on the simulation procedure were given by Köster et al. ${ }^{29}$ and Nikolaychuk et al. ${ }^{10}$

\section{Results and discussion}

\section{Experimental results}

Gas solubilities of neon, krypton and xenon in propan-2-ol were measured for temperatures between 320 and $480 \mathrm{~K}$ at different mole fractions. The results are depicted in Fig. 1 and summarized in Table 3 with their uncertainties. For the investigated mixtures in the region of low solute mole fractions, a linear increase of the phase equilibrium pressure was observed when the mole fraction of solute was increased at constant temperature. However, this trend changes at higher solute mole fractions, as can be seen in Fig. 1 b) for the system krypton + propan-2-ol at $480 \mathrm{~K}$. Henry's law implies a linear trend only in the infinite dilution region so that gas solubility data at higher solute mole fractions, where a change from the linear trend was observed, were not considered for the calculation of the Henry's law constant. In the present work, the temperature dependent definition of the Henry's law constant was used

$$
H_{i}=\left(p-p_{s}\right) / x_{i}+p_{s}
$$

wherein $p$ is the measured phase equilibrium pressure, $p_{s}$ the saturation pressure of the pure solvent and $x_{i}$ the mole fraction of the solute in the solvent. The Henry's law constant was determined with the least squares fitting method by Williamson ${ }^{30}$ and York. ${ }^{31}$ This method 
was recommended by Cantrell ${ }^{32}$ for linear regression calculations with uncertainties in both variables. The dashed lines in Fig. 1 represent the regressions that resulted from least squares fitting. A good agreement with the experimental data at low mole fractions was found. Henry's law constant data with their standard uncertainties, also determined with the Williamson and York method, are listed in Table 4.

Table 3: Experimental gas solubility data of neon, krypton and xenon in propan-2-ol, respectively, with phase equilibrium pressure $p$ and mole fraction of the gaseous component in the saturated liquid $x_{i}$. The numbers in parentheses indicate the standard uncertainties $u\left(x_{i}\right)$ in the last digit. The standard uncertainty of the temperature measurement was $u(T)=0.04$ $\mathrm{K}$ and $u(p)=0.07 \mathrm{MPa}$ for the pressure measurement. The data are depicted in Fig. 1 .

\begin{tabular}{|c|c|c|c|c|c|c|c|c|}
\hline \multicolumn{3}{|c|}{$\mathrm{Ne}+2-\mathrm{PrOH}$} & \multicolumn{3}{|c|}{$\mathrm{Kr}+2-\mathrm{PrOH}$} & \multicolumn{3}{|c|}{$\mathrm{Xe}+2-\mathrm{PrOH}$} \\
\hline$T$ & $p$ & $x_{\mathrm{Ne}}$ & $T$ & $p$ & $x_{\mathrm{Kr}}$ & $T$ & $p$ & \\
\hline K & $\mathrm{MPa}$ & $\mathrm{mol} / \mathrm{mol}$ & $\mathrm{K}$ & $\mathrm{MPa}$ & $\mathrm{mol} / \mathrm{mol}$ & $\mathrm{K}$ & $\mathrm{MPa}$ & $\mathrm{mol} / \mathrm{mol}$ \\
\hline 330 & 2.83 & $0.0063(9)$ & 320 & 0.31 & $0.0055(3)$ & 360 & 0.33 & $0.0086(5)$ \\
\hline 330 & 7.43 & $0.0141(9)$ & 320 & 0.59 & $0.0111(3)$ & 360 & 0.61 & $0.0197(5)$ \\
\hline 330 & 10.37 & $0.019(1)$ & 320 & 1.12 & $0.0215(3)$ & 360 & 0.95 & $0.0350(6)$ \\
\hline 330 & 14.11 & $0.027(1)$ & 320 & 1.31 & $0.0248(3)$ & 420 & 1.00 & $0.0096(7)$ \\
\hline 360 & 2.42 & $0.0066(9)$ & 400 & 0.73 & $0.0051(5)$ & 420 & 1.42 & $0.0219(8)$ \\
\hline 360 & 6.17 & $0.015(1)$ & 400 & 1.11 & $0.0128(5)$ & 420 & 1.87 & $0.0393(9)$ \\
\hline 360 & 8.32 & $0.020(1)$ & 400 & 1.42 & $0.0177(6)$ & 480 & 3.25 & $0.012(1)$ \\
\hline 360 & 11.61 & $0.028(1)$ & 400 & 1.83 & $0.0241(6)$ & 480 & 3.74 & $0.027(2)$ \\
\hline 390 & 2.24 & $0.007(1)$ & 400 & 2.09 & $0.0277(6)$ & 480 & 4.24 & $0.049(2)$ \\
\hline 390 & 5.54 & $0.015(1)$ & 480 & 3.18 & $0.0078(7)$ & & & \\
\hline 390 & 6.95 & $0.021(1)$ & 480 & 3.37 & $0.0158(7)$ & & & \\
\hline 390 & 9.71 & $0.029(1)$ & 480 & 3.67 & $0.0264(8)$ & & & \\
\hline 420 & 2.35 & $0.008(1)$ & 480 & 4.28 & $0.0309(9)$ & & & \\
\hline 420 & 4.60 & $0.016(1)$ & 480 & 4.54 & $0.0349(9)$ & & & \\
\hline 420 & 6.08 & $0.022(1)$ & & & & & & \\
\hline 420 & 8.14 & $0.031(1)$ & & & & & & \\
\hline 450 & 3.04 & $0.008(1)$ & & & & & & \\
\hline 450 & 4.50 & $0.018(2)$ & & & & & & \\
\hline 450 & 5.71 & $0.024(2)$ & & & & & & \\
\hline 450 & 7.23 & $0.034(2)$ & & & & & & \\
\hline 480 & 3.73 & $0.009(2)$ & & & & & & \\
\hline 480 & 5.14 & $0.020(2)$ & & & & & & \\
\hline 480 & 5.93 & $0.027(2)$ & & & & & & \\
\hline 480 & 6.96 & $0.038(2)$ & & & & & & \\
\hline
\end{tabular}



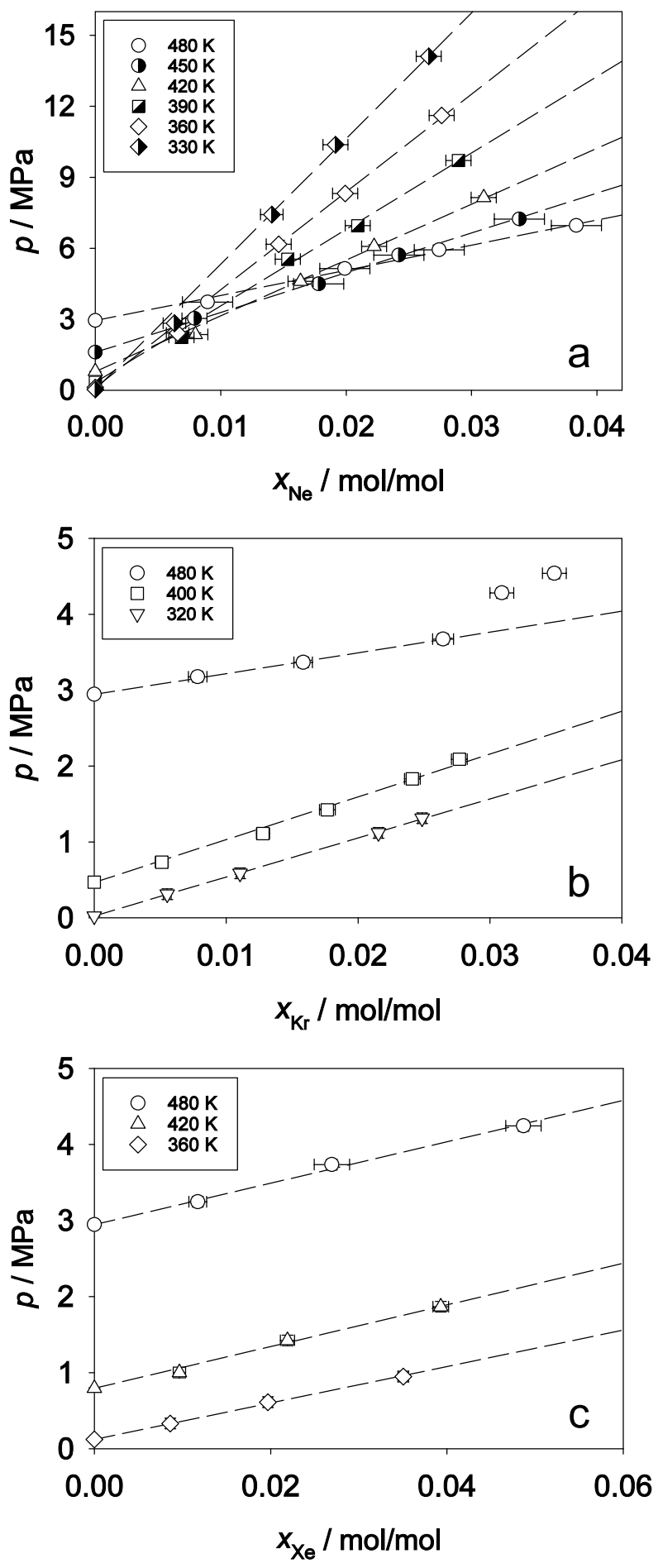

Figure 1: Experimental gas solubility data from the present work for: a) neon, b) krypton and c) xenon in propan-2-ol. The dashed regression lines were employed to determine the Henry's law constant. 
Table 4: Henry's law constant of neon, krypton and xenon in propan-2-ol from the present gas solubility measurements. The numbers in parentheses indicate the standard uncertainties $u\left(H_{i}\right)$ in the last $\operatorname{digit}(\mathrm{s})$.

\begin{tabular}{cc|cc|cc}
\hline \hline \multicolumn{2}{c|}{$\mathrm{Ne}+2-\mathrm{PrOH}$} & \multicolumn{2}{|c|}{$\mathrm{Kr}+2-\mathrm{PrOH}$} & \multicolumn{2}{|c}{$\mathrm{Xe}+2-\mathrm{PrOH}$} \\
\hline$T$ & $H_{\mathrm{Ne}}$ & $T$ & $H_{\mathrm{Kr}}$ & $T$ & $H_{\mathrm{Xe}}$ \\
$\mathrm{K}$ & $\mathrm{MPa}$ & $\mathrm{K}$ & $\mathrm{MPa}$ & $\mathrm{K}$ & $\mathrm{MPa}$ \\
\hline 330 & $530(11)$ & 320 & $51.6(3)$ & 360 & $24.1(4)$ \\
360 & $413(7)$ & 400 & $57(1)$ & 420 & $28(1)$ \\
390 & $323(7)$ & 480 & $30.4(5)$ & 480 & $30.2(9)$ \\
420 & $237(5)$ & & & & \\
450 & $170(3)$ & & & & \\
480 & $109(2)$ & & & & \\
\hline \hline
\end{tabular}

\section{Simulation results}

Henry's law constant data were predicted by molecular simulation for all noble gases in water, methanol, ethanol and propan-2-ol, respectively. The temperature was varied between 42.5 and $95 \%$ of the critical temperature of water for the aqueous systems, while for the alcoholic systems, the temperature ranged between 50 and $95 \%$ of the solvent's critical temperature. Simulation results were compared with literature data listed in Table 5, with experimental values of the present work and from preceding publications of our group. ${ }^{10,11}$ The Henry's law constant as a function of temperature is illustrated in Fig. 2, showing all 24 binary systems. The solvents are arranged column-wise and ordered by increasing molecular size, starting with water. The noble gases are arranged vertically, also ordered by their molecular size and starting with helium on the top. This presentation allows for the observation of qualitative systematic trends of Henry's law constant as a function of temperature for this set of binary systems.

\section{Noble gases in water}

For the binary systems with water as a solvent, which are depicted in the left column of Fig. 2, it can be seen that the Henry's law constant of all noble gases increases with temperature and goes through a maximum. However, the temperature where the Henry's law constant is 

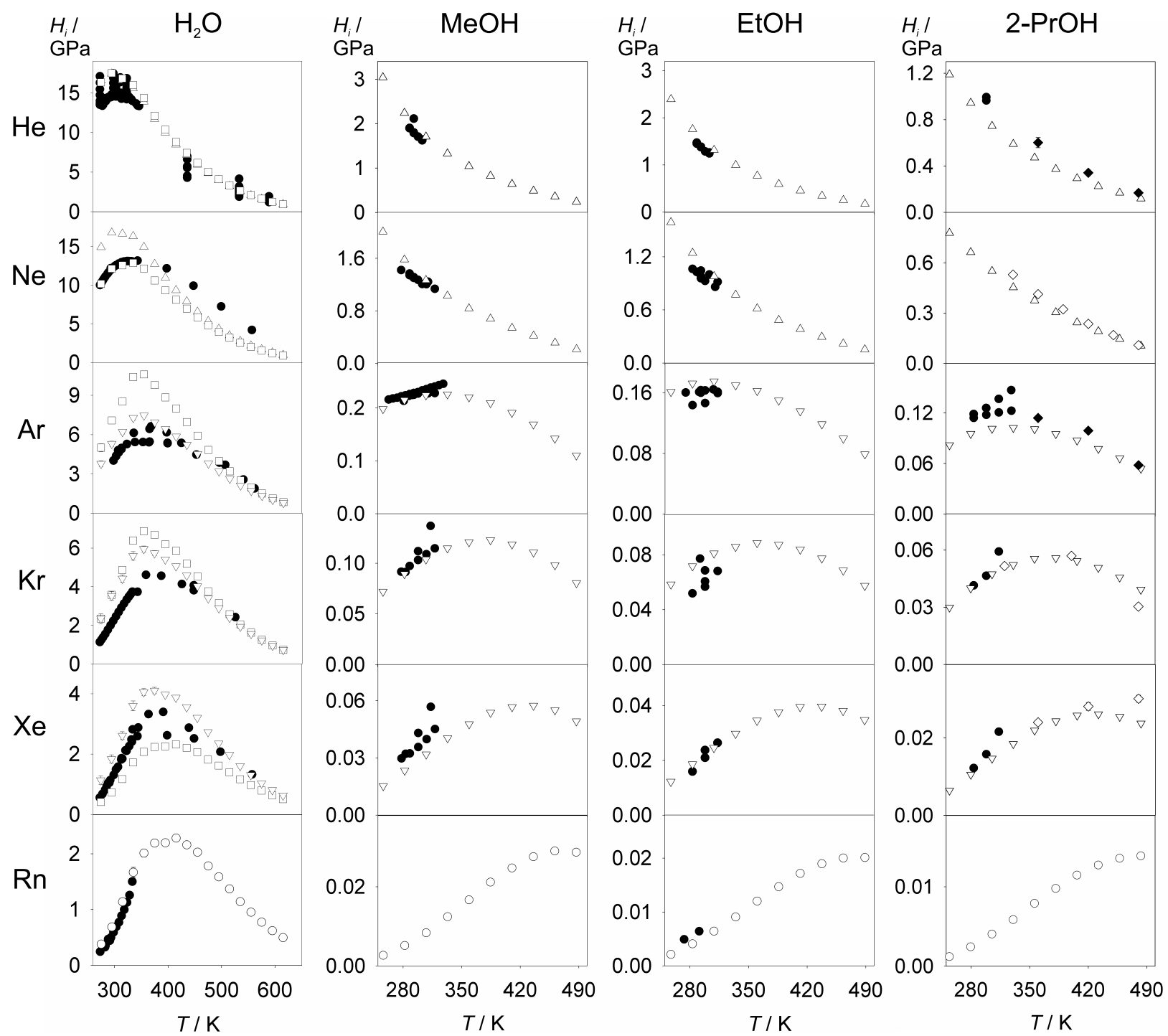

Figure 2: Henry's law constant of noble gases in water, methanol, ethanol and propan-2-ol. Experimental data from the literature $(\bullet)$, molecular simulation using models from Warr et al. ( $\square),{ }^{22}$ Vrabec et al. $(\nabla),{ }^{23}$ Mick et al. (O), ${ }^{24}$ this work $(\Delta)$, experimental values from preceding publications of our group $(\diamond)^{10,11}$ and present experimental work $(\diamond)$. The statistical uncertainties of the present data are mostly within symbol size. 
maximal differs systematically. It is lowest at a temperature of about $295 \mathrm{~K}$ for helium and increases with the molecular size of the noble gas so that the Henry's law constant of radon in water exhibits its maximum at $415 \mathrm{~K}$. Moreover, the highest values of the Henry's law constant are present for helium + water, having the maximum at $17.5 \mathrm{GPa}$. Following the order of the noble gases, it can be seen that the Henry's law constant decreases gradually so that the maximum value of $2.28 \mathrm{GPa}$ is lowest for radon + water. This effect is caused by the different dispersive interaction of the solutes, which is quantified by the energy parameter $\epsilon$ of the LJ model, cf. Table 2. A larger magnitude of dispersion leads to a better solubility and thus to a lower Henry's law constant, which was exemplarily studied for the system of krypton + water by means of a parameter variation in Fig. 3. For a given energy parameter $\epsilon$, an increasing size parameter $\sigma$ leads to a reduced solubility (i.e. higher Henry's law constant) because it is less likely that a dense solvent can accommodate larger solutes. However, the dispersive energy, which raises solubility, has a stronger effect so that solubility increases along the noble gas series.

The results for different solutes are discussed in the following. For helium + water, simulations were carried out employing two different parameter sets for the helium model (Warr et al. and this work), where the results agree well with each other, while the experimental data for temperatures below $350 \mathrm{~K}$ scatter widely and tend to be lower than the predicted values. For higher temperatures, only few experimental data are available in the literature, but they are in good agreement with the present results. For neon + water, two different molecular models for neon (Warr et al. and this work) were employed and it can be seen that results from the model by Warr et al. are in good agreement with the experimental literature data at low temperatures, while the present model overestimates the Henry's law constant in this region so that it is not suitable for this mixture. However, the results from both simulation models coincide at higher temperatures, but are lower than the experimental literature data.

For the noble gases argon, krypton and xenon, molecular models from Warr et al. and 

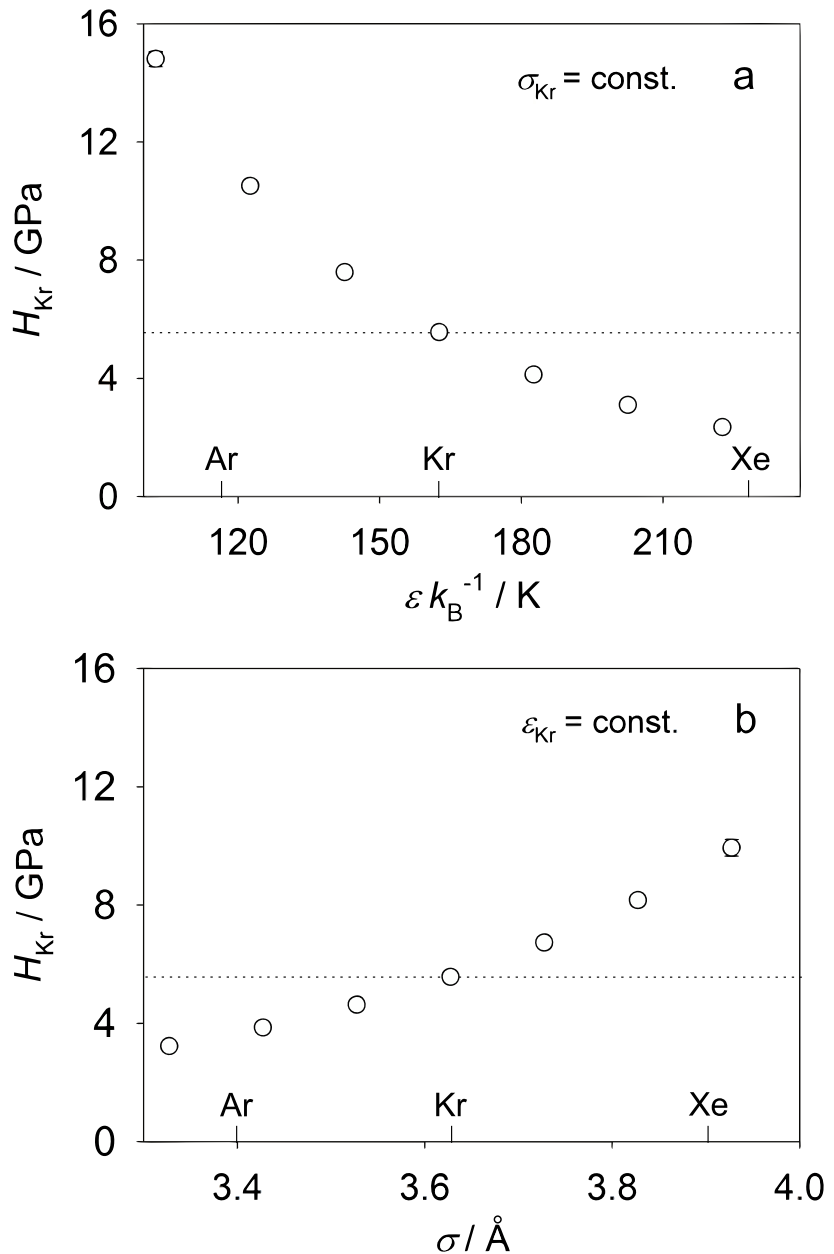

Figure 3: Influence of the LJ parameters of the solute on the predicted Henry's law constant for krypton + water at $355 \mathrm{~K}$. In panel a), the energy parameter was varied, keeping the size parameter constant, while this variation was reverse in panel b). The dashed lines represent the Henry's law constant for the original LJ parameters for krypton. 
from Vrabec et al. were used, respectively. Large deviations from the reference data were obtained for argon + water with the model by Warr et al., while the model by Vrabec et al. is suitable. Both models lead to a maximum of the Henry's law constant at the same temperature of about $355 \mathrm{~K}$, which is consistent with the experimental literature data.

The simulation results from both models overestimate the Henry's law constant for krypton + water at temperatures below $475 \mathrm{~K}$, while the deviation is smaller for the model by Vrabec et al. However, the predicted temperature where the Henry's law constant exhibits its maximum agrees with the experimental data from the literature for both models. Furthermore, the results from simulation as well as the experimental reference data coincide at higher temperatures.

For xenon + water, the results obtained with the model from Warr et al. are lower than the experimental literature data, while the model from Vrabec et al. predicts too high values, but has a better agreement at high temperatures above $500 \mathrm{~K}$. Furthermore, the latter model predicts a temperature of the Henry's law constant maximum that is slightly lower than the experimental value, whereas the model by Warr et al. overestimates this temperature.

For the prediction of the Henry's law constant of radon + water, a molecular model by Mick et al. was employed for the solute. The limited experimental literature data cover only the low temperature range up to $333 \mathrm{~K}$, where the maximum of the Henry's law constant is not reached. Present simulation results are in good agreement with these values so that it can be assumed that the estimated Henry's law constant at higher temperatures is reliable as well.

\section{Noble gases in alcohols}

Binary systems with the solvents methanol, ethanol and propan-2-ol are shown in the second, third and fourth column of Fig. 2, respectively. It can be seen that the Henry's law constant decreases with raising temperature in cases of helium and neon as a solute. For argon, krypton and xenon, the Henry's law constant increases with raising temperature and goes 
through a maximum. Again, the temperature of the Henry's law constant maximum increases with the molecular size of the noble gas. For the alcoholic radon solutions, a maximum of the Henry's law constant can only be observed for the solvent methanol at a temperature of about $461 \mathrm{~K}$, while the predicted values for the solvents ethanol and propan-2-ol monotonically increase with raising temperature over the entire investigated range. As for water, the largest Henry's law constant values were found for the systems with helium, while the values decrease gradually for larger noble gases.

For systems with helium and neon, molecular models from the present work were employed in the simulations, while models from Vrabec et al. were used for argon, krypton and xenon. For radon, a molecular model from Mick et al. was used.

Experimental data for the alcoholic solutions are sparse and only available for temperatures below $350 \mathrm{~K}$. Preceding investigations of our group and the present work provide experimental Henry's law constant data of all noble gases, except for radon, for the solvent propan-2-ol over a wide temperature range up to $480 \mathrm{~K}$ and allow for an adequate evaluation of the present simulation results.

The predicted values from molecular simulation are in good agreement with the literature data and present experimental results for all considered alcoholic solutions of the solutes helium and neon. For the systems with argon, it can be stated that the predicted values for methanol are in line with data by Lannung, ${ }^{33}$ while the data by Pachuliya et al. ${ }^{34}$ do not indicate a maximum of the Henry's law constant so that their trend is inconsistent with the observed overall systematic trend. For argon + ethanol, the simulation results are slightly higher than the experimental literature data, but the predicted temperature of the Henry's law constant maximum agrees well. The results for argon + propan-2-ol tend to be lower than the experimental data, but coincide at higher temperatures. For this system, it also can be seen from the experimental data by Gorelov et al. ${ }^{35}$ and Nikolaychuck et al. ${ }^{10}$ that the temperature of the Henry's law constant maximum was predicted correctly. However, the experimental data by Prorokov et al. ${ }^{36}$ and Krestov et al. ${ }^{37}$ do not indicate a maximum 
so that these disagree with the overall trend.

For krypton + methanol, the predicted values of the Henry's law constant are in good agreement with the data by Abrosimov et al., ${ }^{38}$ while the data by Makranczy ${ }^{39}$ show a different trend with a considerably more pronounced rise of the Henry's law constant as a function of temperature that is not in line with the overall systematic trend. The experimental literature data for krypton + ethanol are inconsistent and the values by Prorokov et al. ${ }^{36,40}$ and Bo et al. ${ }^{41}$ are lower than the simulation results. However, a single Henry's law constant by van Liempt et al. ${ }^{42}$ is in good agreement with the predictions of the present work, but a reasonable assessment of the simulation results is not possible for this system. Observing the results for krypton + propan-2-ol, it can be seen that the predictions agree well with experimental data from the literature and this work in the low and moderate temperature range. In the high temperature region, the results from molecular simulation overestimate the present experimental data point at $480 \mathrm{~K}$.

The experimental literature data for xenon + methanol by Prorokov et al. ${ }^{36}$ and Kudryavtsev et al. ${ }^{43}$ contradict each other. In general, present simulation data are slightly lower than the reference data, but agree well with the trend of Kudryavtsev et al., while the rise of the Henry's law constant as a function of temperature is more pronounced and disagrees with the overall trend of the data by Prorokov et al.

The predictions of the Henry's law constant for xenon + ethanol are in excellent agreement with the experimental literature data. The same applies for the system of xenon + propan-2-ol in the low temperature range. At higher temperatures, the Henry's law constant values by Prorokov et al. ${ }^{36}$ rise more steeply than the predicted data that, however, agree with the present experimental points at temperatures of 360 and $420 \mathrm{~K}$. Nevertheless, the Henry's law constant maximum that was predicted at a temperature of about 432 K by molecular simulation was not validated by the present experiments, where no maximum was observed so that the predicted values underestimate the Henry's law constant for temperatures above $420 \mathrm{~K}$. 
For the systems with radon as a solute, no experimental data for the Henry's law constant were available for the solvents methanol and propan-2-ol so that the simulation data were not evaluated. For radon + ethanol, two experimental values were found in the literature, which are in line with the present simulation data.

Looking at all binary systems that are depicted in Fig. 2, another systematic trend can be seen for the Henry's law constant with respect to the solvents. It is highest for water and decreases gradually from the left to the right so that the Henry's law constant is lowest for the systems with propan-2-ol. Considering that the solubility is inverse to the Henry's law constant, it can be summarized that the solubility increases with increasing molecular size for both the solutes and solvents. These macroscopic effects can be explained by the intermolecular interactions. In general, it is well known that the solubility of non-polar solutes in polar solvents is low ${ }^{44}$ because of the strong attractive forces within the pure solvents. All present solvents are very polar, while the respective electric dipole moment and the correlated attractive force decrease with increasing molecular size. ${ }^{45}$ However, with increasing molecular size, their hydrocarbon content rises so that the particularly attractive hydroxyl group gradually loses its dominance. Thereby, the molar solvent density decreases, which entails more voids for accommodating solute molecules. On the other hand, the monatomic noble gases are non-polar and can only be polarized temporarily. The polarizability is lowest for helium because it has only two electrons, while for a larger atomic size and a rising number of electrons, the polarizability increases so that the formation of temporary dipoles is highest for radon. ${ }^{46}$ Thus, it appears that the lowest solubility is present for helium + water, where the solvent with the strongest attractive force is combined with the solute that forms a temporary dipole most unlikely.

However, it should be noted that the solutes in the present molecular simulations were modeled with the simple LJ potential, which is non-polar and does not explicitly consider polarization effects. Here, the LJ energy parameter $\epsilon$ that increases with molecular size (cf. Table 2), represents the dispersive force and is suitable to adequately predict the solubility 
systematics for the entire set of investigated systems.

Table 5: Literature references for experimental Henry's law constant data for the investigated binary systems.

\begin{tabular}{|c|c|c|c|c|}
\hline & water & methanol & ethanol & propan-2-ol \\
\hline helium & $\begin{array}{l}\text { Morrison et al. }{ }^{47} \\
\text { Pray et al. }{ }^{49} \\
\text { Weiss }{ }^{52} \\
\text { Hawkins et al. }{ }^{54} \\
\text { Cady et al. }{ }^{55} \\
\text { Wiebe et al. }^{56}\end{array}$ & $\begin{array}{l}\text { Lannung }^{33} \\
\text { Clever et al. }^{50} \\
\text { Lühring et al. }^{53}\end{array}$ & $\begin{array}{l}\text { Lannung }^{33} \\
\text { Bo et al. }\end{array}$ & $\begin{array}{l}\text { Yamamoto et al. } \\
\text { Sada et al. }\end{array}$ \\
\hline neon & $\begin{array}{l}\text { Krause et al. } \\
\text { Potter et al. }\end{array}$ & $\begin{array}{l}\text { Lannung }^{33} \\
\text { Kudryavtsev et al. }{ }^{43}\end{array}$ & $\begin{array}{l}\text { Lannung }^{33} \\
\text { Krestov et al. }\end{array}$ & \\
\hline argon & $\begin{array}{l}\text { Potter et al. }{ }^{58} \\
\text { Crovetto et al. }\end{array}$ & $\begin{array}{l}\text { Lannung }^{33} \\
\text { Pachuliya et al. }\end{array}$ & $\begin{array}{l}\text { Lannung }^{33} \\
\text { Prorokov et al. }\end{array}$ & $\begin{array}{l}\text { Prorokov et al. }{ }^{36} \\
\text { Krestov et al. } \\
\text { Gorelov et al. }^{35}\end{array}$ \\
\hline krypton & $\begin{array}{l}\text { Potter et al. }{ }^{58} \\
\text { Crovetto et al. } \\
\text { Krause et al. }^{57}\end{array}$ & $\begin{array}{l}\text { Makranczy } \\
\text { Abrosimov et al. }\end{array}$ & $\begin{array}{l}\text { Prorokov et al. }{ }^{36,40} \\
\text { Bo et al. } \\
\text { van Liempt et al. }{ }^{42}\end{array}$ & Prorokov et al. $^{36}$ \\
\hline xenon & $\begin{array}{l}\text { Morrison et al. } \\
\text { Potter et al. } \\
{ }^{58} \\
\text { Crovetto et al. } \\
\text { Krause et al. }^{57}\end{array}$ & $\begin{array}{l}\text { Kudryavtsev et al. } \\
\text { Prorokov et al. }^{46}\end{array}$ & Prorokov et al. $^{36,40}$ & Prorokov et al. $^{36}$ \\
\hline radon & $\begin{array}{l}\text { Lewis et al. } \\
\text { Ramstedt }^{62}\end{array}$ & & Ramstedt $^{62}$ & \\
\hline
\end{tabular}

\section{Conclusions}

Henry's law constant data for all noble gases in the pure solvents water, methanol, ethanol and propan-2-ol were predicted over a wide temperature range. In a first step, gas solubility measurements were carried out for neon, xenon and krypton in propan-2-ol at temperatures between 320 and $480 \mathrm{~K}$, where only limited or no experimental data were available in the literature. These experimental results were employed to determine Henry's law constant values. This allowed for the evaluation of predicted data from molecular simulations that were conducted in a predictive manner, i.e. without any binary parameters, on the basis 
of several molecular force field models. New Lennard-Jones parameters were proposed for helium and neon.

The predicted Henry's law constant values were presented as a function of temperature for 24 binary systems and compared with experimental data from this work and the literature. Different molecular models for a given solute may lead to considerably different predictions and it was shown which models are suitable for the respective binary solute-solvent systems. The solubility behavior for the entire set of systems was investigated, where it was pointed out that the solubility increases in the order of rising molecular size, both for the solvent and the solute. Another systematic trend was observed for the temperature dependence of the Henry's law constant, which exhibits a maximum at low temperatures for small solutes. With rising solute size, the temperature of the Henry's law constant maximum increases. In summary, the present work provides consistent Henry's law constant data for 24 relevant binary mixtures for temperatures up to the near-critical region of the solvents so that the available database was extended considerably.

\section{Associated Content}

The supporting information provides Henry's law constant data for the noble gases in water, methanol, ethanol and propan-2-ol as predicted by molecular simulation. Furthermore, a specification of Lennard-Jones parameters for helium and neon is described, the force field parameters of the solvents are listed and typical input files for the simulation of Henry's law constant with $m s 2$ are presented.

\section{References}

(1) Mersmann, A.; Kind, M.; Stichlmair, J. Thermal Separation Technology; Springer: Berlin, 2011. 
(2) Calibo, R. L.; Matsumura, M.; Takahashi, J.; Kataoka, H. Ethanol Stripping by Pervaporation Using Porous PTFE Membrane. J. Ferment. Technol. 1987, 65, 665-674.

(3) Sander, R. Compilation of Henry's Law Constants for Inorganic and Organic Species of Potential Importance in Environmental Chemistry. 1999; Max-Planck Institute of Chemistry, Air Chemistry Department Mainz, Germany.

(4) Bamford, H. A.; Poster, D. L.; Baker, J. E. Henry's Law Constants of Polychlorinated Biphenyl Congeners and Their Variation with Temperature. J. Chem. Eng. Data 2000, 45, 1069-1074.

(5) Brockbank, S. A.; Russon, J. L.; Giles, N. F.; Rowley, R. L.; Wilding, W. V. Critically Evaluated Database of Environmental Properties: The Importance of Thermodynamic Relationships, Chemical Family Trends, and Prediction Methods. Int. J. Thermophys. 2013, 34, 2027-2045.

(6) Häring, H.; Ahner, C.; Belloni, A. Industrial Gases Processing; Wiley: Weinheim, 2008; Vol. 646 .

(7) Růžička, J.; Beneš, J.; Bolek, L.; Markvartová, V. Biological Effects of Noble Gases. Physiol. Res. 2007, 56, S39-S44.

(8) Rettich, T.; Battino, R.; Wilhelm, E. Solubility of Gases in Liquids. 18. High-Precision Determination of Henry Fugacities for Argon in Liquid Water at 2 to $40^{\circ} \mathrm{C}$. J. Solution Chem. 1992, 21, 987-1004.

(9) Nobandegani, F. F.; Gavahian, M.; Roeintan, A. Modeling the Vapor-Liquid Equilibrium of Mixtures Involving Noble Gases, Alkanes, and Refrigerants and some Ionic Liquids Using Perturbed Hard-Sphere Equation of State. J. Appl. Sol. Chem. Model. 2013, 2, 85-95. 
(10) Nikolaychuk, P. A.; Linnemann, M.; Muñoz-Muñoz, Y. M.; Baumhögger, E.; Vrabec, J. Experimental and Computational Study on the Solubility of Argon in Propan-2-ol at High Temperatures. Chem. Lett. 2017, 46, 990-991.

(11) Nikolaychuk, P. A.; Linnemann, M.; Baumhögger, E.; Vrabec, J. Èksperimental'noe izučenie rastvorimosti geliâ v propan-2-ole pri temperaturah 360, 420 i 480 K. Izvestîa Saratovskogo universiteta. Novâ̂ Seriâ. Seriâa Himiâ. Biologiâ. Ėkologiâ 2017, 17, 155162.

(12) Köster, A.; Jiang, T.; Rutkai, G.; Glass, C. W.; Vrabec, J. Automatized determination of fundamental equations of state based on molecular simulations in the cloud. Fluid Phase Equilib. 2016, 425, 84-92.

(13) Rutkai, G.; Köster, A.; Guevara-Carrion, G.; Janzen, T.; Schappals, M.; Glass, C. W.; Bernreuther, M.; Wafai, A.; Stephan, S.; Kohns, M.; Reiser, S.; Deublein, S.; Horsch, M.; Hasse, H.; Vrabec, J. ms2: A molecular simulation tool for thermodynamic properties, release 3.0. Comput. Phys. Commun. 2017, 221, 343-351.

(14) Windmann, T.; Linnemann, M.; Vrabec, J. Fluid Phase Behavior of Nitrogen + Acetone and Oxygen + Acetone by Molecular Simulation, Experiment and the Peng-Robinson Equation of State. J. Chem. Eng. Data 2014, 59, 28-38.

(15) Linnemann, M.; Vrabec, J. Vapor-Liquid Equilibria of Nitrogen + Diethyl Ether and Nitrogen $+1,1,1,2,2,4,5,5,5$-Nonafluoro-4-(trifluoromethyl)-3-pentanone by Experiment, Peng-Robinson and PC-SAFT Equations of State. J. Chem. Eng. Data 2017, 62, 2110-2114.

(16) Lemmon, E. W.; Span, R. Short Fundamental Equations of State for 20 Industrial Fluids. J. Chem. Eng. Data 2006, 51, 785-850.

(17) Katti, R.; Jacobsen, R.; Stewart, R.; Jahangiri, M. Thermodynamic Properties of Neon 
for Temperatures from the Triple Point to $700 \mathrm{~K}$ at Pressures to $700 \mathrm{MPa}$. In: Advances in Cryogenic Engineering; Springer: Boston, 1986; Vol. 31.

(18) Gross, J.; Sadowski, G. Application of the Perturbed-Chain SAFT Equation of State to Associating Systems. Ind. Eng. Chem. Res. 2002, 41, 5510-5515.

(19) Abascal, J. L.; Vega, C. A general purpose model for the condensed phases of water: TIP4P/2005. J. Chem. Phys. 2005, 123, 234505.

(20) Schnabel, T.; Srivastava, A.; Vrabec, J.; Hasse, H. Hydrogen Bonding of Methanol in Supercritical $\mathrm{CO}_{2}$ : Comparison between ${ }^{1} \mathrm{H}$ NMR Spectroscopic Data and Molecular Simulation Results. J. Phys. Chem. B 2007, 111, 9871-9878.

(21) Schnabel, T.; Vrabec, J.; Hasse, H. Henry's law constants of methane, nitrogen, oxygen and carbon dioxide in ethanol from 273 to $498 \mathrm{~K}$ : Prediction from molecular simulation. Fluid Phase Equilib. 2005, 233, 134-143, and 2006, 239, 125-126.

(22) Warr, O.; Ballentine, C. J.; Mu, J.; Masters, A. Optimizing Noble Gas-Water Interactions via Monte Carlo Simulations. J. Phys. Chem. B 2015, 119, 14486-14495.

(23) Vrabec, J.; Stoll, J.; Hasse, H. A Set of Molecular Models for Symmetric Quadrupolar Fluids. J. Phys. Chem. B 2001, 105, 12126-12133.

(24) Mick, J. R.; Soroush Barhaghi, M.; Potoff, J. J. Prediction of Radon-222 Phase Behavior by Monte Carlo Simulation. J. Chem. Eng. Data 2016, 61, 1625-1631.

(25) Lorentz, H. Ueber die Anwendung des Satzes vom Virial in der kinetischen Theorie der Gase. Ann. Phys. 1881, 248, 127-136.

(26) Berthelot, D. Sur le mélange des gaz. C. R. Acad. Sci. 1898, 126, 1703-1706.

(27) Shing, K.; Gubbins, K.; Lucas, K. Henry constants in non-ideal fluid mixtures: Computer simulation and theory. Mol. Phys. 1988, 65, 1235-1252. 
(28) Widom, B. Some Topics in the Theory of Fluids. J. Chem. Phys. 1963, 39, 2808-2812.

(29) Köster, A.; Thol, M.; Vrabec, J. Molecular Models for the Hydrogen Age: Hydrogen, Nitrogen, Oxygen, Argon, and Water. J. Chem. Eng. Data 2018, 63, 305-320.

(30) Williamson, J. Least-squares fitting of a straight line. Can. J. Phys. 1968, 46, 18451847.

(31) York, D. Least squares fitting of a straight line with correlated errors. Earth Planet. Sci. Lett. 1968, 5, 320-324.

(32) Cantrell, C. Technical Note: Review of methods for linear least-squares fitting of data and application to atmospheric chemistry problems. Atmos. Chem. Phys. 2008, 8, $5477-5487$.

(33) Lannung, A. The Solubilities of Helium, Neon and Argon in Water and some Organic Solvents. J. Am. Chem. Soc. 1930, 52, 68-80.

(34) Pachuliya, Z.; Khoruzhenko, V.; Zheleznyak, N. 1984; Oniitekhim, Code 548 KHP D84, 1-6.

(35) Gorelov, V.; Vinogradov, V.; Krestov, G. 1983; Oniitekhim, Code 1142 KHP - D83, $1-7$.

(36) Prorokov, V.; Dolotov, V.; Krestov, G. Solubility and Thermodynamic Characteristics for the Dissolution of Argon, Krypton and Xenon in Water and Monohydric Alcohols. Russ. J. Phys. Chem. 1984, 58, 1153-1154.

(37) Krestov, G.; Vinogradov, G.; Parfenyuk, V. Solubility of Argon in Binary-Mixtures such as Methyl-Alcohol. Isopropyl-Alcohol and Propyl-Alcohol. Russ. J. Phys. Chem. 1980, 25, 323-325. 
(38) Abrosimov, V.; Ivanov, E.; Lebedeva, E. Y. Solubility and Thermodynamics of Solvation of Krypton in Aqueous-Methanol Solutions of Urea at $101325 \mathrm{~Pa}$ and 278-318 K. Russ. J. Gen. Chem. 2005, 75, 1010-1016.

(39) Makranczy, J. Solubility of Gases in Normal Alcohols. Hung. J. Ind. Chem. 1979, 7, $41-46$.

(40) Prorokov, V.; Dolotov, V.; Krestov, G. Experiments on Thermodynamic Characteristics of Dissolution Enthalpy of Noble-Gases in Ethanol. Russ. J. Phys. Chem. 1982, 56, $116-117$.

(41) Bo, S.; Battino, R.; Wilhelm, E. Solubility of Gases in Liquids. 19. Solubility of He, Ne, $\mathrm{Ar}, \mathrm{Kr}, \mathrm{Xe}, \mathrm{N}_{2}, \mathrm{O}_{2}, \mathrm{CH}_{4}, \mathrm{CF}_{4}$, and $\mathrm{SF}_{6}$ in Normal 1-Alkanols $n-\mathrm{C}_{l} \mathrm{H}_{2 l+1} \mathrm{OH}(1 \leq l \leq$ 11) at 298.15 K. J. Chem. Eng. Data 1993, 38, 611-616.

(42) Van Liempt, J.; Van Wijk, W. Die Löslichkeit von Krypton in verschiedenen Flüssigkeiten. Rec. Trav. Chim. Pays-Bas 1937, 56, 632-634.

(43) Kudryavtsev, S.; Strakhov, A.; Krestov, G. Solubility of Neon and Xenon in Differently Deuteriated Water-Methanol Mixtures. Russ. J. Phys. Chem. 1986, 60, 286.

(44) Mirejovsky, D.; Arnett, E. M. Heat Capacities of Solution for Alcohols in Polar Solvents and the New View of Hydrophobic Effects. J. Am. Chem. Soc. 1983, 105, 1112-1117.

(45) Nelson Jr, R. D.; Lide Jr, D. R.; Maryott, A. A. Selected Values of Electric Dipole Moments for Molecules in the Gas Phase. NSRDS-NBS 10, Washington, DC. 1967.

(46) Nicklass, A.; Dolg, M.; Stoll, H.; Preuss, H. Ab initio energy-adjusted pseudopotentials for the noble gases Ne through Xe: Calculation of atomic dipole and quadrupole polarizabilities. J. Chem. Phys. 1995, 102, 8942-8952.

(47) Morrison, T.; Johnstone, N. Solubilities of the Inert Gases in Water. J. Chem. Soc. 1954, 3441-3446. 
(48) Yamamoto, H.; Ichikawa, K.; Tokunaga, J. Solubility of Helium in Methanol + Water, Ethanol + Water, 1-Propanol + Water, and 2-Propanol + Water solutions at $25^{\circ} \mathrm{C} . \mathrm{J}$. Chem. Eng. Data 1994, 39, 155-157.

(49) Pray, H. A.; Schweickert, C.; Minnich, B. H. Solubility of Hydrogen, Oxygen, Nitrogen, and Helium in Water at Elevated Temperatures. Ind. Eng. Chem. 1952, 44, 1146-1151.

(50) Clever, H.; Reddy, G. The Salting Out of Helium and Argon by Sodium Iodide in Methanol and in Water at $30^{\circ}$ C. J. Chem. Eng. Data 1963, 8, 191-192.

(51) Sada, E.; Kito, S.; Ito, Y. Solubility of Nitrous Oxide in the Mixtures of Alcohols and Water: Comparison with Pierotti's Gas Solubility Theory. Ind. Eng. Chem. Fund. $1975,14,232-237$.

(52) Weiss, R. F. Solubility of Helium and Neon in Water and Seawater. J. Chem. Eng. Data 1971, 16, 235-241.

(53) Lühring, P.; Schumpe, A. Gas Solubilities $\left(\mathrm{H}_{2}, \mathrm{He}, \mathrm{N}_{2}, \mathrm{CO}, \mathrm{O}_{2}, \mathrm{Ar}, \mathrm{CO}_{2}\right)$ in Organic Liquids at 293.2 K. J. Chem. Eng. Data 1989, 34, 250-252.

(54) Hawkins, J. A.; Shilling, C. W. Helium Solubility in Blood at Increased Pressures. J. Biol. Chem. 1936, 113, 649-653.

(55) Cady, H. P.; Elsey, H. M.; Berger, E. V. The Solubility of Helium in Water. J. Am. Chem. Soc. 1922, 44, 1456-1461.

(56) Wiebe, R.; Gaddy, V. The Solubility of Helium in Water at 0, 25, 50 and $75^{\circ} \mathrm{C}$ and at Pressures to 1000 Atmospheres. J. Am. Chem. Soc. 1935, 57, 847-851.

(57) Krause, D.; Benson, B. B. The Solubility and Isotopic Fractionation of Gases in Dilute Aqueous Solution. IIa. Solubilities of the Noble Gases. J. Solution Chem. 1989, 18, 823-873. 
(58) Potter, R. W.; Clynne, M. A. The Solubility of the Noble Gases He, Ne, Ar, Kr, and Xe in Water up to the Critical Point. J. Solution Chem. 1978, r, 837-844.

(59) Krestov, G.; Patsatsiya, G. Solubility and Thermodynamics of Solution of Neon in Water-Ethyl Alcohol Mixtures. Izv. Vys. Ucheb. Zaved. Khim. Khim. Tekn. 1969, 12, $1333-1337$.

(60) Crovetto, R.; Fernández-Prini, R.; Japas, M. L. Solubilities of inert gases and methane in $\mathrm{H}_{2} \mathrm{O}$ and in $\mathrm{D}_{2} \mathrm{O}$ in the temperature range of 300 to $600 \mathrm{~K}$. J. Chem. Phys. 1982, $76,1077-1086$.

(61) Lewis, C.; Hopke, P. K.; Stukel, J. J. Solubility of Radon in Selected Perfluorocarbon Compounds and Water. Ind. Eng. Chem. Res. 1987, 26, 356-359.

(62) Ramstedt, E. Sur la solubilité de l'émanation du radium dans les liquides organiques. le Radium 1911, 8, 253-256. 
Graphical TOC Entry

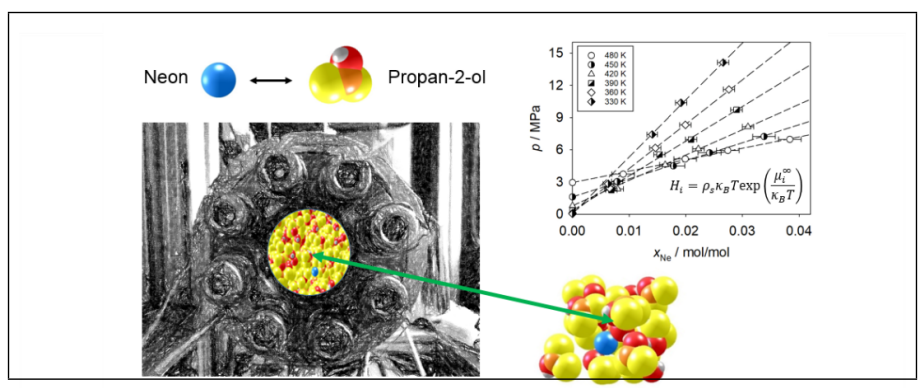




\title{
Supporting information for:
}

\section{Henry's Law Constant of Noble Gases in}

\section{Water, Methanol, Ethanol and Isopropanol by Experiment and Molecular Simulation}

\author{
Matthias Linnemann, ${ }^{\dagger}$ Pavel Anatolyevich Nikolaychuk, ${ }^{\ddagger}$ Y. Mauricio \\ Muñoz-Muñoz, ${ }^{\ddagger}$ Elmar Baumhögger, ${ }^{\ddagger}$ and Jadran Vrabec ${ }^{*, \dagger}$ \\ $\dagger$ Thermodynamics and Process Engineering, Technical University of Berlin, \\ Ernst-Reuter-Platz 1, 10623 Berlin, Germany \\ $\ddagger$ Thermodynamics and Energy Technology, University of Paderborn, Warburger Straße 100, \\ 33098 Paderborn, Germany \\ E-mail: vrabec@tu-berlin.de
}

Phone: +49 (0)30 314-22755. Fax: +49 (0)30 314-22406

\begin{abstract}
This supporting information provides Henry's law constant data for the noble gases in water, methanol, ethanol and propan-2-ol predicted by molecular simulation. Furthermore, a specification of Lennard-Jones parameters for helium and neon is described, the force field parameters of the solvents are listed and typical input files for the simulation of Henry's law constant with $m s 2$ are presented.
\end{abstract}




\section{Lennard-Jones Parameters}

The present work provides new LJ parameters for He and Ne. For this purpose, the maximum value of the second virial coefficient of the LJ fluid, which is $B^{\max } / \sigma^{3}=1.1064$ at $k_{B} T^{\max } / \epsilon=$ $25.1732{ }^{1}$ was compared with the maximum of the second virial coefficient $B^{\max }$ of these two gases at their respective maximum temperatures $T^{\max }$, as depicted in Fig. 1 . For this purpose, highly accurate EOS by Ortiz Vega $^{2}$ and Katti et al. ${ }^{3}$ were employed to determine the second virial coefficient of helium and neon, respectively. The LJ parameters for the two pure substances were then defined as $\epsilon / k_{\mathrm{B}}=T_{i}^{\max } / T_{*}^{\max }$ and $\sigma=\sqrt[3]{B_{i}^{\max } / B_{*}^{\max }}$, respectively, resulting in $\epsilon_{\mathrm{He}} / k_{\mathrm{B}}=6.934 \mathrm{~K}, \sigma_{\mathrm{He}}=2.64 \AA$ and $\epsilon_{\mathrm{Ne}} / k_{\mathrm{B}}=23.867 \mathrm{~K}, \sigma_{\mathrm{Ne}}=2.72 \AA$. These parameters were employed to estimate the gas density by calculating the second and third virial coefficients at VLE conditions of methanol, ethanol and propan-2-ol, which were in good agreement with literature data. However, it was found that the Henry's law constant did not coincide well with the experimental data so that the $\sigma$ values were readjusted to obtain a better agreement, yielding $\sigma_{\mathrm{He}}=2.952 \AA$ and $\sigma_{\mathrm{Ne}}=3.048 \AA$.

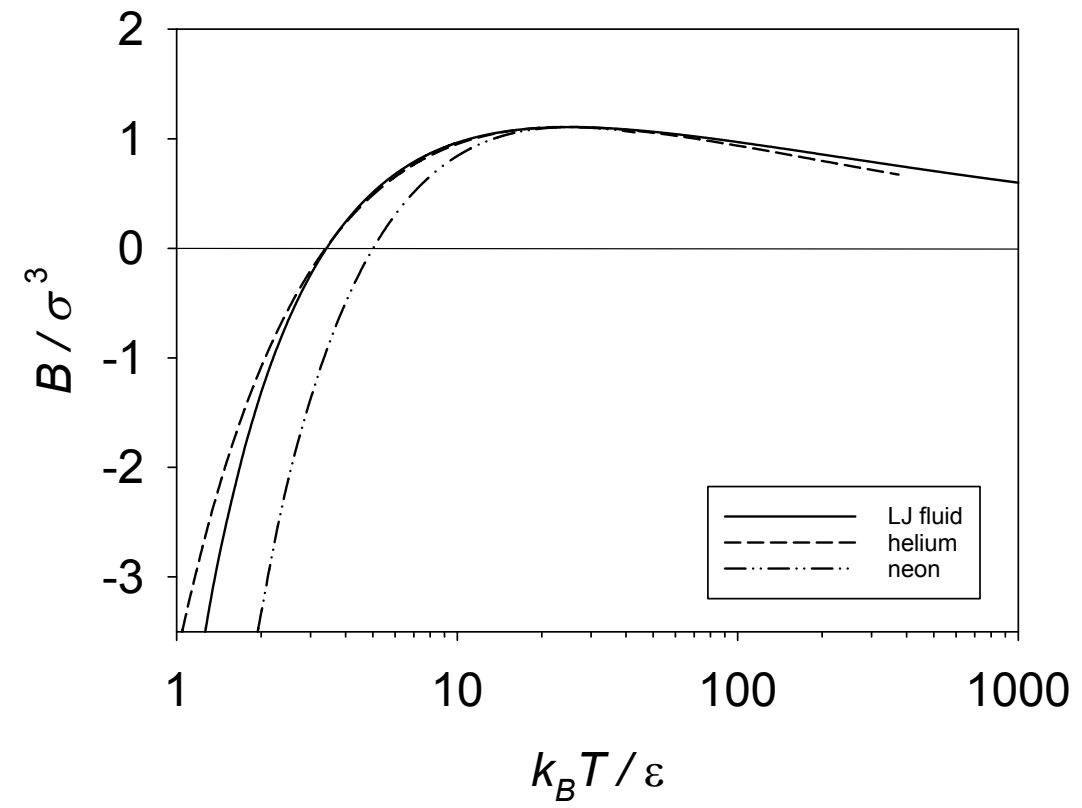

Figure S 1: Second virial coefficient as a function of temperature for the LJ fluid and for helium and neon with adjusted $\epsilon$ and $\sigma$. 


\section{Solvents force field parameters}

Table S 1: Force field parameters for water, ${ }^{4}$ methanol, ${ }^{5}$ ethanol ${ }^{6}$ and propan-2-ol ${ }^{7}$ employed in the present work.

\begin{tabular}{lcccccc}
\hline \hline site & $x / \AA$ & $y / \AA$ & $z / \AA$ & $\sigma / \AA$ & $\epsilon / k_{\mathrm{B}} / \mathrm{K}$ & $q / q_{e}$ \\
\hline \multicolumn{5}{c}{ water } \\
\hline $\mathrm{O}$ & 0 & 0 & 0 & 3.1589 & 93.2 & \\
$\mathrm{H}$ & 0.58588 & 0.75695 & 0 & & & 0.5564 \\
$\mathrm{H}$ & 0.58588 & -0.75695 & 0 & & 0.5564 \\
$\mathrm{PC}^{\mathrm{a}}$ & 0.1546 & 0 & 0 & & -1.1128 \\
\hline \multicolumn{7}{c}{ methanol } \\
\hline $\mathrm{CH}_{3}$ & 0.76603 & 0.01338 & 0 & 3.7543 & 120.5917 & 0.2475 \\
$\mathrm{O}$ & -0.65646 & -0.06389 & 0 & 3.03 & 87.8791 & -0.6787 \\
$\mathrm{H}$ & -1.00499 & 0.81459 & 0 & & & 0.4312 \\
\hline \multicolumn{7}{c}{ ethanol } \\
\hline $\mathrm{CH}_{3}$ & -1.47077 & -0.33835 & 0 & 3.6072 & 120.15 & \\
$\mathrm{CH}$ & 0.09277 & 0.88328 & 0 & 3.4612 & 86.291 & 0.2556 \\
$\mathrm{O}$ & 1.17155 & -0.45098 & 0 & 3.1495 & 85.0534 & -0.6971 \\
$\mathrm{H}$ & 2.04916 & -0.08587 & 0 & & & 0.4415 \\
\hline \multicolumn{7}{c}{ propan-2-ol } \\
\hline $\mathrm{CH}_{3}$ & -1.21412 & -0.76352 & -0.10424 & 3.9052 & 106.05 & \\
$\mathrm{CH}$ & 1.31845 & -0.57256 & -0.09082 & 3.9052 & 106.05 & \\
$\mathrm{CH}$ & 0.0016 & 0.02693 & 0.37199 & 3.2383 & 20.2 & 0.3097 \\
$\mathrm{O}$ & -0.02613 & 1.36732 & -0.16452 & 3.1538 & 85.9035 & -0.7472 \\
$\mathrm{H}$ & -0.79426 & 1.86518 & 0.09883 & & 0.4375 \\
\hline \hline
\end{tabular}

${ }^{\mathrm{a}} \mathrm{PC}$ : point charge 


\section{Henry's law constant data by molecular simulation}

Table S 2: Henry's law constant data from molecular simulation for helium and neon in water, employing molecular force field models for the solutes from Warr et al. ${ }^{8}$ and this work. Statistical uncertainties are denoted by $\delta H_{i}$.

\begin{tabular}{c|rc|cc|cc|cc}
\hline \hline$T$ & $H_{i}$ & $\delta H_{i}$ & $H_{i}$ & $\delta H_{i}$ & $H_{i}$ & $\delta H_{i}$ & $H_{i}$ & $\delta H_{i}$ \\
$\mathrm{~K}$ & $\mathrm{GPa}$ & $\mathrm{GPa}$ & $\mathrm{GPa}$ & $\mathrm{GPa}$ & $\mathrm{GPa}$ & $\mathrm{GPa}$ & $\mathrm{GPa}$ & $\mathrm{GPa}$ \\
\hline & \multicolumn{3}{|c|}{$\mathrm{He}+\mathrm{H}_{2} \mathrm{O}$} & \multicolumn{4}{c}{$\mathrm{Ne}+\mathrm{H}_{2} \mathrm{O}$} \\
\hline & \multicolumn{2}{|c|}{ this work } & \multicolumn{2}{c|}{ Warr } & \multicolumn{2}{|c}{ this } & work & \multicolumn{2}{c}{ Warr } \\
\hline 275 & 16.570 & 0.214 & 16.331 & 0.211 & 14.923 & 0.269 & 10.187 & 0.183 \\
295 & 17.427 & 0.139 & 17.506 & 0.140 & 16.795 & 0.189 & 12.142 & 0.136 \\
315 & 16.562 & 0.121 & 16.836 & 0.123 & 16.668 & 0.164 & 12.595 & 0.124 \\
335 & 15.550 & 0.087 & 15.993 & 0.090 & 16.352 & 0.129 & 12.899 & 0.102 \\
355 & 13.890 & 0.056 & 14.374 & 0.058 & 14.955 & 0.086 & 12.170 & 0.070 \\
375 & 11.697 & 0.052 & 12.137 & 0.053 & 12.742 & 0.073 & 10.627 & 0.061 \\
395 & 9.984 & 0.033 & 10.378 & 0.035 & 10.966 & 0.049 & 9.339 & 0.042 \\
415 & 8.473 & 0.031 & 8.816 & 0.033 & 9.360 & 0.045 & 8.121 & 0.039 \\
435 & 7.140 & 0.023 & 7.432 & 0.024 & 7.914 & 0.033 & 6.976 & 0.029 \\
455 & 5.929 & 0.017 & 6.165 & 0.018 & 6.563 & 0.024 & 5.862 & 0.021 \\
475 & 4.859 & 0.013 & 5.042 & 0.013 & 5.350 & 0.017 & 4.828 & 0.015 \\
495 & 3.974 & 0.009 & 4.114 & 0.009 & 4.352 & 0.011 & 3.966 & 0.010 \\
515 & 3.224 & 0.008 & 3.330 & 0.009 & 3.506 & 0.011 & 3.221 & 0.010 \\
535 & 2.576 & 0.007 & 2.651 & 0.007 & 2.775 & 0.008 & 2.567 & 0.008 \\
555 & 2.048 & 0.006 & 2.101 & 0.006 & 2.186 & 0.007 & 2.036 & 0.007 \\
575 & 1.597 & 0.006 & 1.632 & 0.006 & 1.687 & 0.007 & 1.581 & 0.006 \\
595 & 1.225 & 0.005 & 1.248 & 0.005 & 1.282 & 0.006 & 1.208 & 0.005 \\
615 & 0.929 & 0.005 & 0.943 & 0.005 & 0.963 & 0.005 & 0.913 & 0.005 \\
\hline \hline
\end{tabular}


Table S 3: Henry's law constant data from molecular simulation for argon and krypton in water, employing molecular force field models for the solutes from Warr et al. ${ }^{8}$ and Vrabec et al. ${ }^{9}$ Statistical uncertainties are denoted by $\delta H_{i}$.

\begin{tabular}{c|rc|cc|cc|cc}
\hline \hline$T$ & \multicolumn{1}{|c|}{$H_{i}$} & $\delta H_{i}$ & $H_{i}$ & $\delta H_{i}$ & $H_{i}$ & $\delta H_{i}$ & $H_{i}$ & $\delta H_{i}$ \\
$\mathrm{~K}$ & $\mathrm{GPa}$ & $\mathrm{GPa}$ & $\mathrm{GPa}$ & $\mathrm{GPa}$ & $\mathrm{GPa}$ & $\mathrm{GPa}$ & $\mathrm{GPa}$ & $\mathrm{GPa}$ \\
\hline & \multicolumn{4}{|c|}{$\mathrm{Ar}+\mathrm{H}_{2} \mathrm{O}$} & \multicolumn{3}{c}{$\mathrm{Kr}+\mathrm{H}_{2} \mathrm{O}$} \\
\hline & \multicolumn{2}{|c}{ Warr } & \multicolumn{2}{|c|}{ Vrabec } & \multicolumn{2}{c}{ Warr } & \multicolumn{2}{c}{ Vrabec } \\
\hline 275 & 5.004 & 0.301 & 3.784 & 0.227 & 2.349 & 0.246 & 2.346 & 0.246 \\
295 & 7.085 & 0.264 & 5.303 & 0.198 & 3.580 & 0.228 & 3.527 & 0.225 \\
315 & 8.526 & 0.235 & 6.214 & 0.171 & 4.866 & 0.215 & 4.419 & 0.196 \\
335 & 10.405 & 0.254 & 7.283 & 0.178 & 6.393 & 0.252 & 5.589 & 0.220 \\
355 & 10.597 & 0.183 & 7.463 & 0.129 & 6.875 & 0.181 & 5.955 & 0.157 \\
375 & 9.786 & 0.143 & 6.951 & 0.102 & 6.690 & 0.152 & 5.732 & 0.130 \\
395 & 8.842 & 0.099 & 6.426 & 0.072 & 6.199 & 0.100 & 5.410 & 0.087 \\
415 & 7.994 & 0.087 & 5.863 & 0.064 & 5.857 & 0.087 & 5.059 & 0.075 \\
435 & 6.965 & 0.060 & 5.232 & 0.045 & 5.190 & 0.059 & 4.577 & 0.052 \\
455 & 5.928 & 0.042 & 4.537 & 0.032 & 4.537 & 0.043 & 4.027 & 0.038 \\
475 & 4.839 & 0.029 & 3.811 & 0.023 & 3.756 & 0.028 & 3.402 & 0.026 \\
495 & 3.979 & 0.018 & 3.200 & 0.015 & 3.148 & 0.018 & 2.883 & 0.017 \\
515 & 3.205 & 0.017 & 2.640 & 0.014 & 2.574 & 0.016 & 2.392 & 0.015 \\
535 & 2.514 & 0.012 & 2.130 & 0.010 & 2.039 & 0.011 & 1.935 & 0.010 \\
555 & 1.971 & 0.009 & 1.710 & 0.008 & 1.619 & 0.009 & 1.559 & 0.008 \\
575 & 1.507 & 0.008 & 1.341 & 0.007 & 1.252 & 0.007 & 1.226 & 0.007 \\
595 & 1.137 & 0.007 & 1.035 & 0.006 & 0.957 & 0.006 & 0.950 & 0.006 \\
615 & 0.854 & 0.005 & 0.793 & 0.005 & 0.730 & 0.005 & 0.732 & 0.005 \\
\hline \hline
\end{tabular}


Table S 4: Henry's law constant data from molecular simulation for xenon and radon in water, employing molecular force field models for the solutes from Warr et al., ${ }^{8}$ Vrabec et al. ${ }^{9}$ and Mick et al. ${ }^{10}$ Statistical uncertainties are denoted by $\delta H_{i}$.

\begin{tabular}{c|cc|cc|cc}
\hline \hline$T$ & $H_{i}$ & $\delta H_{i}$ & $H_{i}$ & $\delta H_{i}$ & $H_{i}$ & $\delta H_{i}$ \\
$\mathrm{~K}$ & $\mathrm{GPa}$ & $\mathrm{GPa}$ & $\mathrm{GPa}$ & $\mathrm{GPa}$ & $\mathrm{GPa}$ & $\mathrm{GPa}$ \\
\hline \multicolumn{4}{|c|}{$\mathrm{Xe}+\mathrm{H}_{2} \mathrm{O}$} \\
\hline \multicolumn{3}{|c|}{ Warr } & \multicolumn{2}{c}{ Vrabec } & \multicolumn{2}{c}{$\mathrm{Rn}+\mathrm{H}_{2} \mathrm{O}$} \\
\hline 275 & 0.412 & 0.051 & 1.135 & 0.142 & 0.379 & 0.057 \\
295 & 0.733 & 0.055 & 1.839 & 0.137 & 0.687 & 0.060 \\
315 & 1.172 & 0.059 & 2.610 & 0.131 & 1.138 & 0.067 \\
335 & 1.724 & 0.079 & 3.597 & 0.164 & 1.667 & 0.089 \\
355 & 2.074 & 0.062 & 4.052 & 0.121 & 2.010 & 0.069 \\
375 & 2.238 & 0.058 & 4.105 & 0.106 & 2.190 & 0.066 \\
395 & 2.257 & 0.040 & 3.969 & 0.070 & 2.195 & 0.044 \\
415 & 2.322 & 0.037 & 3.871 & 0.062 & 2.279 & 0.041 \\
435 & 2.206 & 0.026 & 3.553 & 0.043 & 2.157 & 0.029 \\
455 & 2.069 & 0.020 & 3.202 & 0.031 & 2.027 & 0.022 \\
475 & 1.819 & 0.014 & 2.731 & 0.021 & 1.780 & 0.015 \\
495 & 1.619 & 0.009 & 2.353 & 0.014 & 1.585 & 0.010 \\
515 & 1.398 & 0.009 & 1.974 & 0.012 & 1.369 & 0.009 \\
535 & 1.167 & 0.006 & 1.605 & 0.008 & 1.140 & 0.006 \\
555 & 0.974 & 0.005 & 1.306 & 0.007 & 0.952 & 0.005 \\
575 & 0.792 & 0.004 & 1.034 & 0.006 & 0.773 & 0.004 \\
595 & 0.636 & 0.004 & 0.809 & 0.005 & 0.620 & 0.004 \\
615 & 0.509 & 0.003 & 0.631 & 0.004 & 0.497 & 0.003 \\
\hline \hline
\end{tabular}


Table S 5: Henry's law constant data from molecular simulation for noble gases in methanol, employing molecular force field models for the solutes from Vrabec et al., ${ }^{9}$ Mick et al. ${ }^{10}$ and this work. Statistical uncertainties are denoted by $\delta H_{i}$.

\begin{tabular}{|c|c|c|c|c|c|c|}
\hline $\begin{array}{l}T \\
\mathrm{~K}\end{array}$ & $\begin{array}{c}H_{i} \\
\mathrm{GPa}\end{array}$ & $\begin{array}{l}\delta H_{i} \\
\mathrm{GPa}\end{array}$ & $\begin{array}{c}H_{i} \\
\mathrm{GPa}\end{array}$ & $\begin{array}{l}\delta H_{i} \\
\mathrm{GPa}\end{array}$ & $\begin{array}{c}H_{i} \\
\mathrm{GPa}\end{array}$ & $\begin{array}{l}\delta H_{i} \\
\mathrm{GPa}\end{array}$ \\
\hline & \multicolumn{2}{|c|}{$\mathrm{He}+\mathrm{MeOH}$} & \multicolumn{2}{|c|}{$\mathrm{Ne}+\mathrm{MeOH}$} & \multicolumn{2}{|c|}{$\mathrm{Ar}+\mathrm{MeOH}$} \\
\hline & \multicolumn{2}{|c|}{ this work } & \multicolumn{2}{|c|}{ this work } & \multicolumn{2}{|c|}{ Vrabec } \\
\hline 256.30 & 3.042 & 0.032 & 2.005 & 0.008 & 0.1981 & 0.0017 \\
\hline & 2.243 & 0.0 & 1.580 & 0.00 & 0.2150 & 0.0012 \\
\hline & 706 & & 267 & & 2240 & \\
\hline & & & & & 2257 & 0.0008 \\
\hline & & & 836 & & 2202 & 0.0005 \\
\hline & & & 679 & & 2094 & 0.0004 \\
\hline & 0 & 0.0 & 539 & 0.0 & 0.1910 & 0.0004 \\
\hline & 489 & 0.00 & 0.420 & 0.001 & 0.1689 & 0.0003 \\
\hline 46 & 0.359 & 0.00 & 0.313 & 0.001 & 1422 & 0.0003 \\
\hline \multirow[t]{3}{*}{486.97} & 0.240 & 0.001 & 0.214 & 0.001 & 0.1104 & 0.0004 \\
\hline & \multicolumn{2}{|c|}{$\mathrm{Kr}+\mathrm{MeOH}$} & \multicolumn{2}{|c|}{$\mathrm{Xe}+\mathrm{MeOH}$} & \multicolumn{2}{|c|}{$\mathrm{Rn}+\mathrm{MeOH}$} \\
\hline & \multicolumn{2}{|c|}{ Vrabec } & \multicolumn{2}{|c|}{ Vrabec } & \multicolumn{2}{|c|}{ Mick } \\
\hline 256.30 & 0.0720 & 0.0008 & 0.0153 & 0.0003 & 0.0027 & 0.0001 \\
\hline 281.93 & 895 & & 0234 & & 0.0052 & 0.0001 \\
\hline 307.56 & 039 & & 318 & & 0084 & 0.0001 \\
\hline & 149 & & 404 & & & 0.0001 \\
\hline & 209 & & 477 & & & 0.0001 \\
\hline & & & & & & 0.0001 \\
\hline & & & & & & 0.0001 \\
\hline & & & 574 & & 0.0276 & 0.0001 \\
\hline & & & & & .0290 & 0.0001 \\
\hline 486.97 & 806 & 0003 & 492 & 0.0001 & 0.0287 & \\
\hline
\end{tabular}


Table S 6: Henry's law constant data from molecular simulation for noble gases in ethanol, employing molecular force field models for the solutes from Vrabec et al., ${ }^{9}$ Mick et al. ${ }^{10}$ and this work. Statistical uncertainties are denoted by $\delta H_{i}$.

\begin{tabular}{c|cc|cc|cc}
\hline \hline$T$ & $H_{i}$ & $\delta H_{i}$ & $H_{i}$ & $\delta H_{i}$ & $H_{i}$ & $\delta H_{i}$ \\
$\mathrm{~K}$ & $\mathrm{GPa}$ & $\mathrm{GPa}$ & $\mathrm{GPa}$ & $\mathrm{GPa}$ & $\mathrm{GPa}$ & $\mathrm{GPa}$ \\
\hline & \multicolumn{2}{|c|}{$\mathrm{He}+\mathrm{EtOH}$} & \multicolumn{2}{c|}{$\mathrm{Ne}+\mathrm{EtOH}$} & \multicolumn{2}{c}{$\mathrm{Ar}+\mathrm{EtOH}$} \\
\hline & \multicolumn{2}{|c|}{ this work } & \multicolumn{2}{|c|}{ this work } & \multicolumn{2}{c}{ Vrabec } \\
\hline 257.35 & 2.3937 & 0.0254 & 1.5876 & 0.0102 & 0.1613 & 0.0019 \\
303.09 & 1.7554 & 0.0138 & 1.2418 & 0.0052 & 0.1724 & 0.0013 \\
334.56 & 1.3147 & 0.0074 & 0.9781 & 0.0033 & 0.1752 & 0.0010 \\
360.29 & 0.7695 & 0.0040 & 0.7703 & 0.0014 & 0.1699 & 0.0005 \\
386.03 & 0.5916 & 0.0013 & 0.6152 & 0.0014 & 0.1627 & 0.0005 \\
411.76 & 0.4557 & 0.0010 & 0.3827 & 0.0005 & 0.1358 & 0.0002 \\
437.50 & 0.3441 & 0.0009 & 0.2946 & 0.0004 & 0.1186 & 0.0002 \\
463.23 & 0.2516 & 0.0009 & 0.2193 & 0.0004 & 0.0998 & 0.0002 \\
488.97 & 0.1723 & 0.0009 & 0.1530 & 0.0005 & 0.0790 & 0.0002 \\
\hline & \multicolumn{2}{|c|}{$\mathrm{Kr}+\mathrm{EtOH}$} & \multicolumn{2}{|c|}{$\mathrm{Xe}+\mathrm{EtOH}$} & \multicolumn{2}{c|}{$\mathrm{Rn}+\mathrm{EtOH}$} \\
\hline & \multicolumn{2}{|c|}{ Vrabec } & \multicolumn{2}{|c|}{ Vrabec } & \multicolumn{2}{c}{$\mathrm{Mick}$} \\
\hline 257.35 & 0.0584 & 0.0009 & 0.0122 & 0.0003 & 0.00213 & 0.00006 \\
283.09 & 0.0717 & 0.0007 & 0.0186 & 0.0003 & 0.00408 & 0.00007 \\
308.82 & 0.0811 & 0.0006 & 0.0246 & 0.0002 & 0.00644 & 0.00007 \\
334.56 & 0.0859 & 0.0003 & 0.0297 & 0.0002 & 0.00908 & 0.00006 \\
360.29 & 0.0888 & 0.0003 & 0.0345 & 0.0001 & 0.01202 & 0.00006 \\
386.03 & 0.0874 & 0.0002 & 0.0376 & 0.0001 & 0.01468 & 0.00004 \\
411.76 & 0.0840 & 0.0002 & 0.0395 & 0.0001 & 0.01715 & 0.00004 \\
437.50 & 0.0775 & 0.0001 & 0.0396 & 0.0001 & 0.01895 & 0.00003 \\
463.23 & 0.0686 & 0.0001 & 0.0381 & 0.0001 & 0.02002 & 0.00003 \\
\hline \hline
\end{tabular}


Table S 7: Henry's law constant data from molecular simulation for noble gases in propan-2ol, employing molecular force field models for the solutes from Vrabec et al., ${ }^{9}$ Mick et al. ${ }^{10}$ and this work. Statistical uncertainties are denoted by $\delta H_{i}$.

\begin{tabular}{c|cc|cc|cc}
\hline \hline$T$ & $H_{i}$ & $\delta H_{i}$ & $H_{i}$ & $\delta H_{i}$ & $H_{i}$ & $\delta H_{i}$ \\
$\mathrm{~K}$ & $\mathrm{GPa}$ & $\mathrm{GPa}$ & $\mathrm{GPa}$ & $\mathrm{GPa}$ & $\mathrm{GPa}$ & $\mathrm{GPa}$ \\
\hline & \multicolumn{2}{|c|}{$\mathrm{He}+2-\mathrm{PrOH}$} & \multicolumn{2}{|c|}{$\mathrm{Ne}+2$-PrOH } & \multicolumn{2}{c}{$\mathrm{Ar}+2-\mathrm{PrOH}$} \\
\hline & \multicolumn{2}{|c|}{ this work } & \multicolumn{2}{|c|}{ this work } & \multicolumn{2}{c}{ Vrabec } \\
\hline 254.10 & 1.1888 & 0.0126 & 0.7784 & 0.0041 & 0.0819 & 0.0008 \\
279.60 & 0.9443 & 0.0074 & 0.6634 & 0.0026 & 0.0954 & 0.0006 \\
305.00 & 0.7449 & 0.0042 & 0.5509 & 0.0014 & 0.1015 & 0.0004 \\
330.40 & 0.5895 & 0.0023 & 0.4537 & 0.0009 & 0.1025 & 0.0003 \\
355.80 & 0.4718 & 0.0013 & 0.3754 & 0.0006 & 0.1009 & 0.0002 \\
381.20 & 0.3733 & 0.0008 & 0.3050 & 0.0004 & 0.0953 & 0.0001 \\
406.60 & 0.2932 & 0.0006 & 0.2450 & 0.0003 & 0.0875 & 0.0001 \\
432.00 & 0.2254 & 0.0006 & 0.1920 & 0.0002 & 0.0776 & 0.0001 \\
457.50 & 0.1682 & 0.0006 & 0.1459 & 0.0002 & 0.0664 & 0.0001 \\
482.90 & 0.1190 & 0.0006 & 0.1051 & 0.0002 & 0.0541 & 0.0001 \\
\hline & \multicolumn{2}{|c|}{$\mathrm{Kr}+2-\mathrm{PrOH}$} & \multicolumn{2}{|c|}{$\mathrm{Xe}+2-\mathrm{PrOH}$} & $\mathrm{Rn}+2-\mathrm{PrOH}$ \\
\hline & \multicolumn{2}{|c|}{ Vrabec } & \multicolumn{2}{|c|}{ Vrabec } & \multicolumn{2}{c}{$\mathrm{Mick}$} \\
\hline 254.10 & 0.02995 & 0.00034 & 0.00644 & 0.00010 & 0.00119 & 0.00002 \\
279.60 & 0.04000 & 0.00033 & 0.01056 & 0.00012 & 0.00243 & 0.00003 \\
305.00 & 0.04741 & 0.00023 & 0.01472 & 0.00009 & 0.00404 & 0.00003 \\
330.40 & 0.05225 & 0.00016 & 0.01849 & 0.00007 & 0.00586 & 0.00002 \\
355.80 & 0.05546 & 0.00014 & 0.02198 & 0.00006 & 0.00791 & 0.00003 \\
381.20 & 0.05581 & 0.00010 & 0.02437 & 0.00005 & 0.00979 & 0.00002 \\
406.60 & 0.05428 & 0.00009 & 0.02585 & 0.00005 & 0.01147 & 0.00002 \\
432.00 & 0.05072 & 0.00006 & 0.02618 & 0.00003 & 0.01274 & 0.00002 \\
457.50 & 0.04571 & 0.00007 & 0.02552 & 0.00004 & 0.01359 & 0.00002 \\
482.90 & 0.03925 & 0.00007 & 0.02378 & 0.00004 & 0.01389 & 0.00002 \\
\hline \hline
\end{tabular}




\section{Input parameters for $m s 2$}

Typical input parameters for simulating the Henry's law constant by the Monte-Carlo method in $m s 2$, for the systems water $+(\mathrm{He}, \mathrm{Ne}$, Ar) at $295 \mathrm{~K}$ (a), methanol $+(\mathrm{Ne}$, $\mathrm{Ar}, \mathrm{Kr}, \mathrm{Xe})$ at $307.56 \mathrm{~K}(\mathrm{~b})$, ethanol $+(\mathrm{Ne}, \mathrm{Ar}, \mathrm{Kr}, \mathrm{Xe})$ at $308.82 \mathrm{~K}(\mathrm{c})$ and propan-2-ol + (Ne, Ar, Kr, Xe) at $305 \mathrm{~K}(\mathrm{~d})$. 
(a)

\begin{tabular}{|c|c|}
\hline Units & $=S I$ \\
\hline LengthUnit & $=3$ \\
\hline EnergyUnit & $=100$ \\
\hline MassUnit & $=100$ \\
\hline Simulation & $=M C$ \\
\hline Acceptance & $=0.5$ \\
\hline Ensemble & $=\mathrm{NPT}$ \\
\hline McoRSteps & $=0$ \\
\hline NVTSteps & $=10000$ \\
\hline NPTSteps & $=20000$ \\
\hline Runsteps & $=3000000$ \\
\hline ResultFreq & $=5000$ \\
\hline ErrorsFreq & $=5000$ \\
\hline VisualFreq & $=0$ \\
\hline CutoffMode & $=\mathrm{COM}$ \\
\hline NEnsembles & $=1$ \\
\hline \# Ensemble 1 & \\
\hline Temperature = & 295 \\
\hline Pressure = & 0.0026212 \\
\hline Density & 55.38496 \\
\hline PistonMass $=$ & $2 . \odot \mathrm{E}-7$ \\
\hline OptPressure = & Yes \\
\hline NParticles $=$ & 864 \\
\hline NComponents $=$ & 4 \\
\hline PotModel & $=\mathrm{H} 20 \cdot \mathrm{pm}$ \\
\hline MoleFract & $=1.0$ \\
\hline ChemPotMethod & $=$ none \\
\hline PotModel & $=\mathrm{He} \cdot \mathrm{pm}$ \\
\hline MoleFract & $=0.0$ \\
\hline ChemPotMethod & $=$ Widom \\
\hline NTest & $=3456$ \\
\hline PotModel & $=\mathrm{Ne} \cdot \mathrm{pm}$ \\
\hline MoleFract & $=0.0$ \\
\hline ChemPotMethod & $=$ Widom \\
\hline NTest & $=3456$ \\
\hline PotModel & $=A r \cdot p m$ \\
\hline MoleFract & $=0.0$ \\
\hline ChemPotMethod & $=$ Widom \\
\hline NTest & $=3456$ \\
\hline \multicolumn{2}{|l|}{ eta $=1.0$} \\
\hline \multicolumn{2}{|l|}{$x i=1.0$} \\
\hline \multicolumn{2}{|l|}{ eta $=1.0$} \\
\hline$x i=1.0$ & \\
\hline eta $=1.0$ & \\
\hline
\end{tabular}




$$
\begin{array}{ll}
\mathrm{xi} & =1.0 \\
\text { eta } & =1.0 \\
\mathrm{xi} & =1.0 \\
\text { eta } & =1.0 \\
\mathrm{xi} & =1.0 \\
\text { eta } & =1.0 \\
\mathrm{xi} & =1.0 \\
\text { Cutoff } & =3.0 \\
\text { Epsilon } & =1.0 \mathrm{E} 10
\end{array}
$$

(b)

$$
\begin{aligned}
& \text { Units } \quad=\mathrm{SI} \\
& \text { LengthUnit } \quad=3 \\
& \text { EnergyUnit } \quad=100 \\
& \text { MassUnit } \quad=100 \\
& \text { Simulation }=M C \\
& \text { Acceptance }=0.5 \\
& \text { Ensemble } \quad \text { NPT } \\
& \text { MCORSteps }=0 \\
& \text { NVTSteps } \quad=10000 \\
& \text { NPTSteps } \quad=20000 \\
& \text { Runsteps } \quad=3000000 \\
& \text { ResultFreq } \quad=5000 \\
& \text { ErrorsFreq }=5000 \\
& \text { Visualfreq } \quad=0 \\
& \text { CutoffMode }=\mathrm{COM} \\
& \text { NEnsembles } \quad=1 \\
& \text { \# Ensemble } 1 \\
& \text { Temperature }=307.56 \\
& \text { Pressure }=0.027233 \\
& \text { Density }=24.26159 \\
& \text { PistonMass }=2.0 \mathrm{E}-7 \\
& \text { OptPressure }=\text { Yes } \\
& \text { NParticles }=864 \\
& \text { NComponents }=5 \\
& \text { PotModel }=\mathrm{MeOH} . \mathrm{pm} \\
& \text { MoleFract }=1.0 \\
& \text { ChemPotMethod }=\text { none } \\
& \text { PotModel }=\mathrm{Ne} \cdot \mathrm{pm} \\
& \text { MoleFract }=0.0 \\
& \text { ChemPotMethod }=\text { Widom } \\
& \text { NTest }=3456 \\
& \text { PotModel }=\text { Ar } \cdot \mathrm{pm} \\
& \text { MoleFract }=0.0 \\
& \text { ChemPotMethod }=\text { Widom } \\
& \text { NTest }=3456
\end{aligned}
$$




$$
\begin{aligned}
& \text { PotModel } \quad=\mathrm{Kr} \cdot \mathrm{pm} \\
& \text { MoleFract } \quad=0.0 \\
& \text { ChemPotMethod }=\text { Widom } \\
& \text { NTest }=3456 \\
& \text { PotModel }=\text { Xe. } \cdot \mathrm{pm} \\
& \text { MoleFract }=0.0 \\
& \text { ChemPotMethod }=\text { Widom } \\
& \text { NTest }=3456 \\
& \text { eta }=1.0 \\
& x i=1.0 \\
& \text { eta }=1.0 \\
& x i=1.0 \\
& \text { eta }=1.0 \\
& x i=1.0 \\
& \text { eta }=1.0 \\
& x i=1.0 \\
& \text { eta }=1.0 \\
& x i=1.0 \\
& \text { eta }=1.0 \\
& x i=1.0 \\
& \text { eta }=1.0 \\
& x i=1.0 \\
& \text { Cutoff }=3.0 \\
& \text { Epsilon } \quad=1.0 \mathrm{E} 10 \\
& \text { Units = SI } \\
& \text { LengthUnit }=3 \\
& \text { EnergyUnit } \quad=100 \\
& \text { Massunit } \quad=100 \\
& \text { Simulation }=M C \\
& \text { Acceptance } \quad=0.5 \\
& \text { Ensemble } \quad \text { NPT } \\
& \text { McoRsteps } \quad=0 \\
& \text { NVTSteps } \quad=10000 \\
& \text { NPTSteps } \quad=20000 \\
& \text { Runsteps } \quad=3000000 \\
& \text { ResultFreq } \quad=5000 \\
& \text { ErrorsFreq }=5000 \\
& \text { VisualFreq }=0 \\
& \text { CutoffMode }=\mathrm{COM} \\
& \text { NEnsembles } \quad=1
\end{aligned}
$$




$$
\begin{aligned}
& \text { OptPressure }=\text { Yes } \\
& \text { NParticles }=864 \\
& \text { NComponents }=5 \\
& \text { PotModel }=\mathrm{EtOH} \cdot \mathrm{pm} \\
& \text { MoleFract }=1.0 \\
& \text { ChemPotMethod }=\text { none } \\
& \text { PotModel }=\mathrm{Ne} \cdot \mathrm{pm} \\
& \text { MoleFract } \quad=0.0 \\
& \text { ChemPotMethod }=\text { Widom } \\
& \text { NTest }=3456 \\
& \text { PotModel }=\mathrm{Ar} \cdot \mathrm{pm} \\
& \text { MoleFract } \quad=0 . \odot \\
& \text { ChemPotMethod }=\text { Widom } \\
& \text { NTest }=3456 \\
& \text { PotModel } \quad=\mathrm{Kr} \cdot \mathrm{pm} \\
& \text { MoleFract } \quad=0.0 \\
& \text { ChemPotMethod }=\text { Widom } \\
& \text { NTest }=3456 \\
& \text { PotModel }=\mathrm{Xe} \cdot \mathrm{pm} \\
& \text { MoleFract } \quad=0 . \odot \\
& \text { ChemPotMethod }=\text { Widom } \\
& \text { NTest }=3456 \\
& \text { eta }=1.0 \\
& x i=1.0 \\
& \text { eta }=1.0 \\
& x i=1.0 \\
& \text { eta }=1.0 \\
& x i=1.0 \\
& \text { eta }=1.0 \\
& x i=1.0 \\
& \text { eta }=1.0 \\
& x i=1.0 \\
& \text { eta }=1.0 \\
& x i=1.0 \\
& \text { eta }=1.0 \\
& x i=1.0 \\
& \text { Cutoff }=3.0 \\
& \text { Epsilon } \quad=1.0 \mathrm{E} 10
\end{aligned}
$$


(d)

\begin{tabular}{|c|c|}
\hline Units & $=S I$ \\
\hline LengthUnit & $=3$ \\
\hline EnergyUnit & $=100$ \\
\hline MassUnit & $=100$ \\
\hline Simulation & $=M C$ \\
\hline Acceptance & $=0.5$ \\
\hline Ensemble & $=\mathrm{NPT}$ \\
\hline McoRSteps & $=0$ \\
\hline NVTSteps & $=1000 \odot$ \\
\hline NPTSteps & $=2000 \odot$ \\
\hline Runsteps & $=3000000$ \\
\hline ResultFreq & $=5000$ \\
\hline ErrorsFreq & $=5000$ \\
\hline VisualFreq & $=0$ \\
\hline CutoffMode & $=\mathrm{COM}$ \\
\hline NEnsembles & $=1$ \\
\hline \# Ensemble 1 & \\
\hline Temperature $=$ & 305 \\
\hline Pressure = & $\odot .0 \odot 8797$ \\
\hline Density & 12.89717 \\
\hline PistonMass $=$ & $2 . \odot \mathrm{E}-7$ \\
\hline OptPressure = & Yes \\
\hline NParticles = & 864 \\
\hline NComponents $=$ & 5 \\
\hline PotModel & $=2 \mathrm{PrOH} \cdot \mathrm{pm}$ \\
\hline MoleFract & $=1.0$ \\
\hline ChemPotMethod & $=$ none \\
\hline PotModel & $=\mathrm{Ne} \cdot \mathrm{pm}$ \\
\hline MoleFract & $=0.0$ \\
\hline ChemPotMethod & $=$ Widom \\
\hline NTest & $=3456$ \\
\hline PotModel & $=A r \cdot p m$ \\
\hline MoleFract & $=0.0$ \\
\hline ChemPotMethod & $=$ Widom \\
\hline NTest & $=3456$ \\
\hline PotModel & $=\mathrm{Kr} \cdot \mathrm{pm}$ \\
\hline MoleFract & $=0.0$ \\
\hline ChemPotMethod & $=$ Widom \\
\hline NTest & $=3456$ \\
\hline PotModel & $=\mathrm{Xe} \cdot \mathrm{pm}$ \\
\hline MoleFract & $=0.0$ \\
\hline ChemPotMethod & $=$ Widom \\
\hline NTest & $=3456$ \\
\hline
\end{tabular}




$$
\begin{aligned}
& \text { eta }=1.0 \\
& \text { xi }=1.0 \\
& \text { eta }=1.0 \\
& \text { xi }=1.0 \\
& \text { eta }=1.0 \\
& \text { xi }=1.0 \\
& \text { eta }=1.0 \\
& \text { xi }=1.0 \\
& \text { eta }=1.0 \\
& \text { xi }=1.0 \\
& \text { eta }=1.0 \\
& \text { xi }=1.0 \\
& \text { eta }=1.0 \\
& \text { xi }=1.0= \\
& \text { Cutoff }=3.0 \\
& \text { Epsilon }=1.0 \text { E10 }
\end{aligned}
$$




\section{References}

(1) Thol, M.; Rutkai, G.; Köster, A.; Lustig, R.; Span, R.; Vrabec, J. Equation of State for the Lennard-Jones Fluid. J. Phys. Chem. Ref. Data 2016, 45, 023101.

(2) Ortiz Vega, D. O. A New Wide Range Equation of State for Helium-4; PhD thesis, Texas A\&M University, 2013.

(3) Katti, R.; Jacobsen, R.; Stewart, R.; Jahangiri, M. Thermodynamic Properties of Neon for Temperatures from the Triple Point to $700 \mathrm{~K}$ at Pressures to $700 \mathrm{MPa}$. In: Advances in Cryogenic Engineering; Springer: Boston, 1986; Vol. 31.

(4) Abascal, J. L.; Vega, C. A general purpose model for the condensed phases of water: TIP4P/2005. J. Chem. Phys. 2005, 123, 234505.

(5) Schnabel, T.; Srivastava, A.; Vrabec, J.; Hasse, H. Hydrogen Bonding of Methanol in Supercritical $\mathrm{CO}_{2}$ : Comparison between ${ }^{1} \mathrm{H}$ NMR Spectroscopic Data and Molecular Simulation Results. J. Phys. Chem. B 2007, 111, 9871-9878.

(6) Schnabel, T.; Vrabec, J.; Hasse, H. Henry's law constants of methane, nitrogen, oxygen and carbon dioxide in ethanol from 273 to $498 \mathrm{~K}$ : Prediction from molecular simulation. Fluid Phase Equilib. 2005, 233, 134-143.

(7) Nikolaychuk, P. A.; Linnemann, M.; Muñoz-Muñoz, Y. M.; Baumhögger, E.; Vrabec, J. Experimental and Computational Study on the Solubility of Argon in Propan-2-ol at High Temperatures. Chem. Lett. 2017, 46, 990-991.

(8) Warr, O.; Ballentine, C. J.; Mu, J.; Masters, A. Optimizing Noble Gas-Water Interactions via Monte Carlo Simulations. J. Phys. Chem. B 2015, 119, 14486-14495.

(9) Vrabec, J.; Stoll, J.; Hasse, H. A Set of Molecular Models for Symmetric Quadrupolar Fluids. J. Phys. Chem. B 2001, 105, 12126-12133. 
(10) Mick, J. R.; Soroush Barhaghi, M.; Potoff, J. J. Prediction of Radon-222 Phase Behavior by Monte Carlo Simulation. J. Chem. Eng. Data 2016, 61, 1625-1631. 